\title{
Using Large-Eddy Simulations to Define Spectral and Coherence Characteristics of the Hurricane Boundary Layer for Wind-Energy Applications
}

\author{
Rochelle P. Worsnop ${ }^{1}$ (D) George H. Bryan ${ }^{2}$. \\ Julie K. Lundquist ${ }^{1,3}$. Jun A. Zhang ${ }^{4}$
}

Received: 14 June 2016 / Accepted: 23 May 2017 / Published online: 8 June 2017

(C) The Author(s) 2017. This article is an open access publication

\begin{abstract}
Offshore wind-energy development is planned for regions where hurricanes commonly occur, such as the USA Atlantic Coast. Even the most robust wind-turbine design (IEC Class I) may be unable to withstand a Category-2 hurricane (hub-height wind speeds $>50$ $\mathrm{m} \mathrm{s}^{-1}$ ). Characteristics of the hurricane boundary layer that affect the structural integrity of turbines, especially in major hurricanes, are poorly understood, primarily due to a lack of adequate observations that span typical turbine heights ( $<200 \mathrm{~m}$ above sea level). To provide these data, we use large-eddy simulations to produce wind profiles of an idealized Category-5 hurricane at high spatial $(10 \mathrm{~m})$ and temporal $(0.1 \mathrm{~s})$ resolution. By comparison with unique flight-level observations from a field project, we find that a relatively simple configuration of the Cloud Model I model accurately represents the properties of Hurricane Isabel (2003) in terms of mean wind speeds, wind-speed variances, and power spectra. Comparisons of power spectra and coherence curves derived from our hurricane simulations to those used in current turbine design standards suggest that adjustments to these standards may be needed to capture characteristics of turbulence seen within the simulated hurricane boundary layer. To enable improved design standards for wind turbines to withstand hurricanes, we suggest modifications to account for shifts in peak power to higher frequencies and greater spectral coherence at large separations.
\end{abstract}

Keywords Hurricane boundary layer - Large-eddy simulation · Tropical cyclone . Wind-turbine design

Rochelle P. Worsnop

Rochelle.Worsnop@colorado.edu

1 Department of Atmospheric and Oceanic Sciences, University of Colorado at Boulder, Boulder, CO, USA

2 National Center for Atmospheric Research, Boulder, CO, USA

3 National Renewable Energy Laboratory, Golden, CO, USA

4 NOAA/AOML/Hurricane Research Division, Cooperative Institute for Marine and Atmospheric Studies, University of Miami, Miami, FL, USA 


\section{Introduction}

Plans for wind-power generation in the USA outlined by the Department of Energy (DOE) suggest that the total installed wind capacity in the USA will reach $113 \mathrm{GW}$ by 2030, an increase from the $61 \mathrm{GW}$ installed as of 2013 (DOE 2015). The DOE plan also highlights that $3 \mathrm{GW}$ of future installations will derive from offshore wind turbines. Currently, proposals for offshore wind farms focus on the ocean along the north-east USA, partly because of the lower risk of major hurricanes ( $\geq$ Category 3 on the Saffir-Simpson hurricane wind scale, corresponding to maximum 1-min sustained winds of $49 \mathrm{~m} \mathrm{~s}^{-1}$ or higher at $10 \mathrm{~m}$ a.s.l.) compared to the Atlantic Ocean south of New England and in the Gulf of Mexico (Dvorak et al. 2012). However, as offshore wind development expands, construction in regions vulnerable to destructive hurricanes, such as the US East Coast and the Gulf of Mexico, seems likely.

Even the most robust wind-turbine design (IEC Class I) is not rated to withstand a 10-min mean wind speed $>50 \mathrm{~m} \mathrm{~s}^{-1}$ and a 3 -sec gust of $70 \mathrm{~m} \mathrm{~s}^{-1}$ at hub height (IEC 2007). Since categories of hurricane intensity are assigned based on the peak 1-min sustained wind speed at $10 \mathrm{~m}$ a.s.l., we use the logarithmic wind profile (IEC 2007) to first convert the hub-height 10 -min wind speed to the corresponding wind speed at $10 \mathrm{~m}$ a.s.1. A 10 -min hub-height wind speed of $50 \mathrm{~m} \mathrm{~s}^{-1}$ corresponds to $40 \mathrm{~m} \mathrm{~s}^{-1}$ at $10 \mathrm{~m}$ a.s.l for the same averaging period; then, assuming a wind averaging conversion factor of 0.93 (Harper et al. 2010) to convert the peak 10-min wind speed to a peak 1-min sustained wind speed at $10 \mathrm{~m}$ a.s.1, the 10 -min wind speed of $40 \mathrm{~m} \mathrm{~s}^{-1}$ becomes a $43 \mathrm{~m} \mathrm{~s}^{-1} 1$-min wind speed, which corresponds to a weak Category-2 hurricane. Turbine failure due to hurricanes of this intensity has occurred in Typhoons Maemi (2003) (Ishihara et al. 2005) and Usagi (2013) (Chen and Xu 2016).

Numerous simulations and observations show that hurricanes cause damage to offshore structures. A probabilistic model has estimated that a Category-3 hurricane can seriously damage $46 \%$ of Class I towers in a 50-turbine wind farm designed with the highest current wind standards outlined by the International Electrotechnical Commission (IEC) (Rose et al. 2012). Hurricanes have disastrous effects on the energy infrastructure of the oil industry; in 2005, more than 100 oil-rig platforms were destroyed by hurricanes Katrina and Rita because of wave inundation and excessive wind loads (Cruz and Krausmann 2008). The destruction resulted from inadequate structural design for withstanding a weak Category-3 hurricane, much like the current wind-turbine design standards. More accurate hurricane load estimations are needed to mitigate the destruction of wind turbines; the first step to estimating such loads is to determine the wind characteristics inside the hurricane boundary layer (HBL).

On average, 6.2 hurricanes and 2.3 major hurricanes occur each year in the Atlantic Basin based on a hurricane climatology from 1996-2009 (National Hurricane Center 2016); it is important to determine how the extreme wind speeds associated with these storms affect offshore turbines. Further, hurricane frequency may decrease under future climate change, but future hurricanes may be more intense suggesting an increase in the number of major hurricanes in the late twenty-first century (Bender et al. 2010). As wind farms are designed to last at least 20 years (IEC 2007), major hurricanes pose a substantial risk to offshore wind-turbine development.

Observations of the HBL are rare or incomplete. Dropsondes that descend from aircraft provide a single slant profile, but do not allow for a temporal or spatial analysis at turbinehub height and across the rotor layer. Obvious safety concerns limit reconnaissance flights at turbine heights $(<200 \mathrm{~m}$ a.s.1.). Few offshore towers exist (Archer et al. 2016), and even when instrumented towers exist and are equipped with multiple anemometers, the peak wind 
speed may be underestimated due to under-sampling (Nolan et al. 2014). Unmanned aircraft systems are currently being tested (Cione et al. 2016) to collect continuous hurricane data at relatively high resolution $(1 \mathrm{~Hz})$, but not yet at turbine heights. To address this critical data void, numerical models can be used to estimate wind speed, wind direction, and turbulence in the HBL.

Large-eddy simulations (LES) simulate wind fields and turbulence in hurricanes with a spatial resolution on the order of tens of metres; this detailed information is required to predict how wind speeds and directions in the HBL may influence loads on offshore structures such as wind turbines. The model data are particularly useful for wind-energy applications, because of the lack of observations spanning the height and width of offshore turbines (40-200 m a.s.l.) during major hurricanes. A better understanding of the HBL wind characteristics, and subsequently the loads induced on turbine structures, can support turbine manufacturers in the design of sturdier structures and adequate mechanical systems to withstand the force of major hurricanes.

Turbine load estimators such as the National Renewable Energy Laboratory's FAST model (Jonkman and Buhl 2005) rely on three-dimensional wind fields defined by atmospheric power spectral density and spatial coherence, among other variables. Such simulations rely on theoretical spectral (e.g., Kaimal et al. (1972) and von Kármán and Lin (1951)) and coherence (e.g., IEC exponential coherence (IEC 2007)) models that may not necessarily represent the true inflow ${ }^{1}$ conditions, particularly in a hurricane. Although the IEC 61400-3 (International Electrotechnical Commission Design Requirements for Offshore Wind Turbines) standard states that turbulence models defined for onshore turbine design should also be used for offshore turbine design, Wang et al. (2014) found that the turbulence intensity model referred to as the Normal Turbulence Model (IEC 2007), recommended in the IEC 61400-3, does not represent the non-linear relationship between offshore turbulence intensity and wind speed.

Even though offshore turbine-inflow characteristics during hurricanes are not well understood, previous studies of atmospheric turbulence and possible turbulence effects on loads using observations have examined inflow characteristics of onshore turbines located in nonhurricane conditions. Saranyasoontorn et al. (2004) analyzed the spatial coherence (i.e., the magnitude squared of the cross spectrum normalized by the auto power spectrum of two different signals) of inflow into an onshore turbine using data collected from a turbine and an array of five upwind towers during the Long-term Inflow and Structural Test (LIST) program. Specifically, they found that the IEC exponential coherence model (described in Sect. 3.2) generally performed well for small lateral separations $(\approx 6 \mathrm{~m})$, but for large separations $(\approx 30 \mathrm{~m})$, the model overestimated coherence at most frequencies, but significantly underestimated coherence at low frequencies for wind speeds ranging from $11-13 \mathrm{~m} \mathrm{~s}^{-1}$. We investigate the coherence over various lateral and vertical separations and for $10-\mathrm{m}$ mean wind speeds of 23,47 , and $63 \mathrm{~m} \mathrm{~s}^{-1}$.

Investigations of turbulent spectra in the HBL (Yu et al. 2008; Zhang 2010a; Zhang et al. 2010; Li et al. 2015) have relied on observations from less intense hurricanes (undergoing landfall), without an emphasis on turbine loads. Zhang (2010a) compared normalized spectra and cospectra of wind velocity, temperature, and humidity fluctuations to theoretical spectral curves over the land and ocean based on Monin-Obukhov similarity theory. The velocity spectra in the HBL between outer rain bands compared well with the theoretical surface-layer curves from Miyake et al. (1970) over water and Kaimal et al. (1972) over land. However, Zhang (2010a) found that the frequency of peak power was shifted towards higher frequencies in the HBL, noting a structural difference between the HBL and the boundary layer over land.

1 Inflow herein refers to the airflow into the turbine rotor-disk region. 
These studies have motivated the need to understand the nature of spectral characteristics inside of a hurricane, and serve as motivation for exploring similar spectra for offshore wind-energy applications. We first validate the use of our relatively simple LES set-up by comparison with a more complex LES set-up and a rare dataset of hurricane observations made below $200 \mathrm{~m}$ a.s.l. Then, using high-resolution simulations with the simple LES framework, we perform spectral and coherence analyses of varying wind speeds inside the HBL at heights relevant for offshore wind turbines. We specifically address how turbulence characteristics vary with height and with hurricane mean wind speed.

In Sect. 2, we describe the hurricane model configurations and observational dataset used, while in Sect. 3, we describe how power spectral density and coherence are calculated using LES data. Section 4 presents the results, including suggestions for modified spectral and coherence models for use in three-dimensional wind-field simulators. In Sect. 5, we summarize the results and offer suggestions for future research.

\section{Datasets}

\subsection{Cloud Model I (CM1)}

To assess the HBL, we use idealized simulations with the non-hydrostatic, time-dependent, numerical model, Cloud Model 1 (CM1) (Bryan and Rotunno 2009), with two different configurations, detailed below, created for the purposes of assessing turbulent characteristics inside a major hurricane. We use the CM1 model for all simulations herein. The first model configuration, which we refer to as the Complex set-up simulates the entire inner core of a hurricane, including the eye, eyewall, and rainbands, but this approach is computationally expensive, and so relatively coarse resolution is used. The second configuration, referred to as the Simple set-up, reduces computational expense by simulating only a small portion (approximately $5 \mathrm{~km} \times 5 \mathrm{~km}$ ) of the hurricane, an approach that allows for higher-resolution simulations so that coherence can be calculated across a theoretical turbine rotor layer. A general comparison of the Complex and Simple set-ups appears below.

Both the Complex and Simple set-ups use the same numerical code, which uses RungeKutta time integration with fifth-order advection (Wicker and Skamarock 2002). A prognostic subgrid-scale turbulent kinetic energy (TKE) model (i.e., Deardorff-type TKE scheme) is used to parametrize unresolved turbulence (Stevens et al. 1999; Bryan et al. 2017). For all of the simulations, surface ocean waves are not modelled explicitly; rather, the surface roughness is varied as a function of the time-averaged 10 -m wind speed $(\bar{U})$, as described in Bryan et al. (2017). Herein, for $\bar{U} \geq 25 \mathrm{~m} \mathrm{~s}^{-1}$, the roughness length is held constant at $0.0028 \mathrm{~m}$. This parametrization yields a surface friction velocity $u_{*}$ that varies roughly linear with $\bar{U}$, as suggested by recent observational studies (e.g., Andreas et al. 2012).

\subsubsection{Complex Set-up}

For the Complex set-up, simulation data were generated by first running an axisymmetric (two-dimensional) configuration of the model for twelve days with a horizontal grid spacing of $1 \mathrm{~km}$ and a temporal resolution of $2.5 \mathrm{~s}$ to spin-up the quasi-steady state hurricane as in Bryan (2012). Then, time-averaged fields surrounding the time of maximum hurricane intensity (day 10) over a two-day period were used as initial conditions for a three-dimensional LES. Small-amplitude random perturbations $( \pm 0.1 \mathrm{~K})$ of potential temperature were used to initiate 
turbulent, three-dimensional motions in the model, and the model then was integrated for 4 $\mathrm{h}$ to fully spin-up turbulent flow. Two additional hours of simulation were used to generate data analyzed herein. For more information about the model set-up, such as the sea-surface temperature and microphysical scheme, see Bryan (2012). The total domain size (i.e., entire hurricane and environment) of the simulation is $3000 \mathrm{~km} \times 3000 \mathrm{~km}$ in the horizontal and $25 \mathrm{~km}$ in the vertical with increasingly stretched grid spacing away from a central fine-mesh part of the domain. The fine-mesh LES domain spans $80 \mathrm{~km} \times 80 \mathrm{~km} \times 3 \mathrm{~km}$ centred in the middle of the overall domain. The grid spacing within the fine mesh domain is a constant $62.5 \mathrm{~m}$ in the horizontal and $31.25 \mathrm{~m}$ in the vertical, and the timestep is $0.375 \mathrm{~s}$. Data are provided every timestep for $2 \mathrm{~h}$ over a $7 \times 7$ grid (spanning $437.5 \mathrm{~m} \times 437.5 \mathrm{~m}$ ) at four locations east of the hurricane centre (at radii of 20,25,30, and $35 \mathrm{~km}$ ) from the surface to $500 \mathrm{~m}$ a.s.l. (Table 1). These four locations were chosen so as to provide a range of mean wind speeds (from tropical storm to Category-4 conditions) and to allow for comparison of the Complex set-up with the Simple set-up discussed in Sect. 2.1.2. We examine data up to heights of $200 \mathrm{~m}$ a.s.l. to explore turbulence characteristics that may be relevant to offshore turbines of varying heights. In the LES domain, the quiescence of the eye, as well as small high-speed gusts in excess of $90 \mathrm{~m} \mathrm{~s}^{-1}$ located outside of the eyewall, are apparent (Fig. 1); such high-speed gusts have been observed in nature (Stern et al. 2016).

\subsubsection{Simple Set-up}

The Simple set-up does not simulate a full hurricane, but rather is designed to simulate the conditions in a small region of the hurricane (see Fig. 2) and accounts for the large-scale tendencies associated with a hurricane (e.g., pressure-gradient and centrifugal accelerations) via mesoscale tendency terms, as formulated by Bryan et al. (2017). The Simple set-up uses a LES configuration, so the planetary boundary-layer (PBL) parametrization in the model is removed and the subgrid turbulence model described in the Appendix of Bryan et al. (2017) is employed. In addition, to simplify initial conditions and decrease computational expense, the Simple set-up does not include moisture and therefore employs no microphysical scheme, unlike the Complex set-up. Surface heat fluxes are also neglected (see Bryan et al. 2017) and thus the PBL in these simulations is neutral. As will be shown, wind profiles from the Simple set-up compare well to those from the Complex set-up (Sect. 4.1), suggesting that moisture and surface heat fluxes are not required to create the turbulent conditions. Both setups employ periodic lateral boundary conditions, as is common for LES of the PBL, which is justified if the scales of the horizontal variations in the atmosphere are large compared to the horizontal scale of the domain (e.g., Sommeria 1976). Periodic lateral boundary conditions also allow turbulent eddies to be "recycled" through the domain, which obviates the need to specify turbulent fluctuations at lateral boundaries.

For the Simple set-up, the initial conditions are specified analytically with a small number of parameters, including: the Coriolis parameter $f$, the wind speed above the boundary layer $V$, the radius from the hurricane centre to the Simple set-up domain $R$ (see Fig. 2), and the radial gradient of wind speed above the boundary layer $\mathrm{d} V / \mathrm{d} R$. The mesoscale tendency terms, which use these parameters, are described in detail in Bryan et al. (2017). For the present study, we include subsidence terms (see Siebesma et al. 2003) except that the minimum vertical velocity $w_{\min }$, has a larger amplitude (stated below) and is located at $1 \mathrm{~km}$ a.s.l.

The two set-ups result in greatly different computational expense. Due to the different domain sizes $(5.12 \mathrm{~km} \times 5.12 \mathrm{~km} \times 3 \mathrm{~km}$ for the Simple set-up versus $3000 \mathrm{~km} \times$ $3000 \mathrm{~km} \times 25 \mathrm{~km}$ for the Complex set-up) and inclusion of moisture, the Complex set-up requires approximately two orders of magnitude more CPU hours than the Simple set-up for 


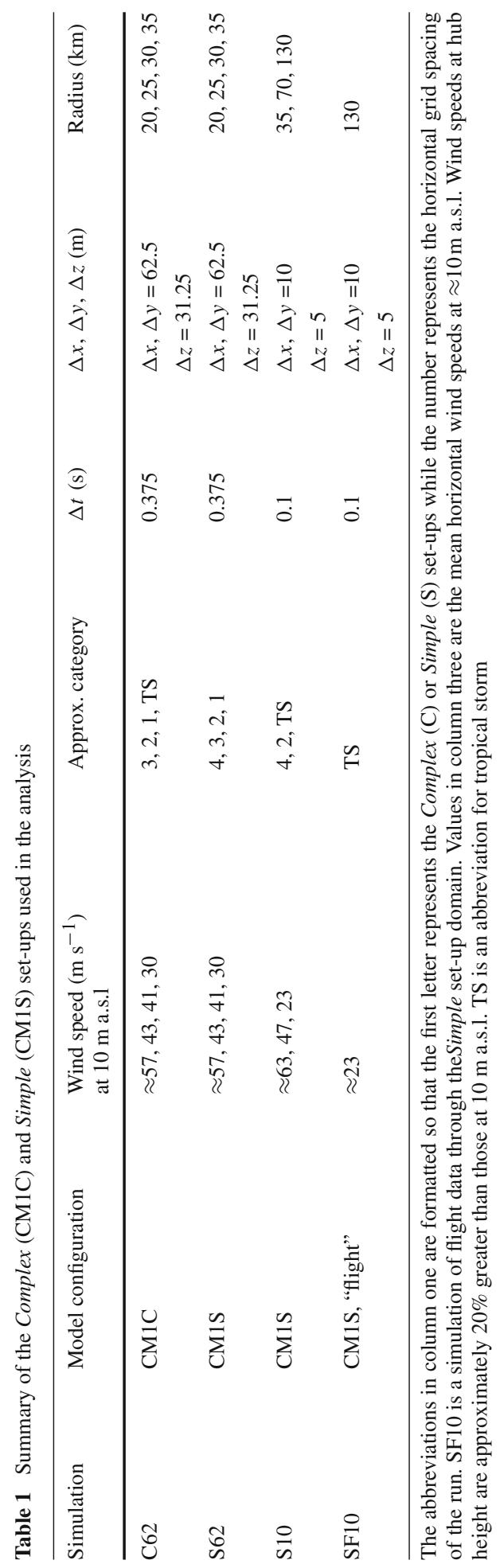




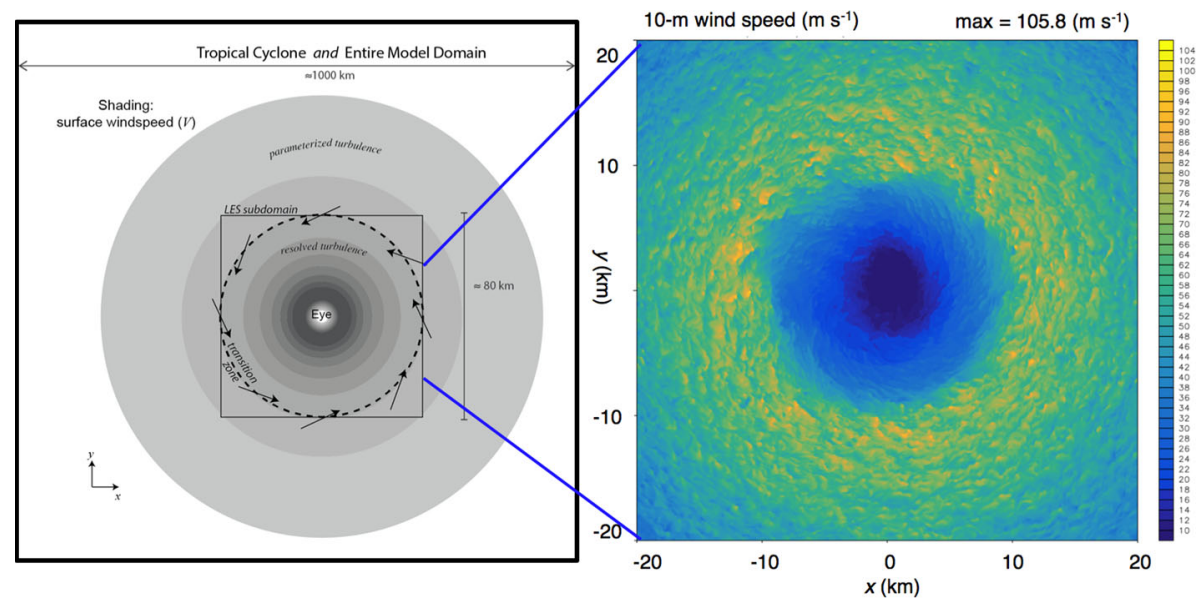

Fig. 1 Complex set-up shown on the left. Instantaneous 10-m wind speed after $6 \mathrm{~h}$ of the LES is shown on the right. The data are from the LES domain with a horizontal grid spacing of $62.5 \mathrm{~m}$ and a temporal resolution of $0.375 \mathrm{~s}$

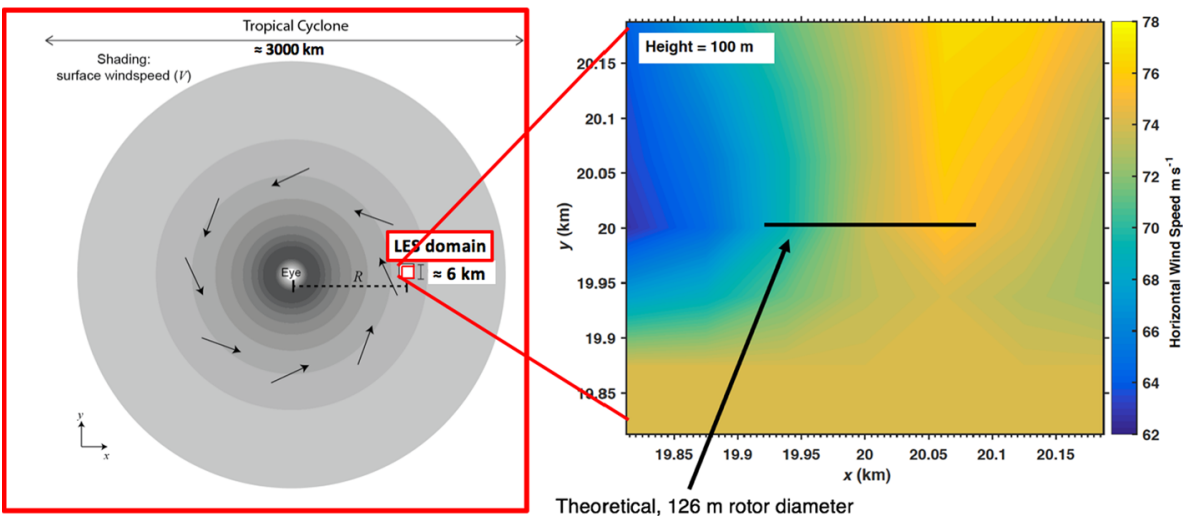

Fig. 2 Simple set-up shown on the left. Instantaneous 100-m horizontal wind speed at a radius of approximately $20 \mathrm{~km}$ is shown on the right. The hurricane centre is at $(0,0)$. The data are from a LES domain with a horizontal grid spacing of $62.5 \mathrm{~m}$ and a temporal resolution of $0.375 \mathrm{~s}$ to match that of the Complex set-up. The black line represents the theoretical rotor span (NREL 5-MW reference wind turbine), looking down on top of the turbine

a simulation using the same horizontal and vertical grid spacing. This great advantage of the Simple set-up allows for temporal and spatial resolutions fine enough for calculations of coherence across the turbine rotor layer (i.e., $\leq 30 \mathrm{~m}$ for at least two points across a typical blade length). However, the Simple set-up is not able to accurately simulate the eyewall of a hurricane, which is dominated by strong mesoscale vertical motions that are not accounted for in the Simple framework. Therefore, only locations outside the radius of maximum wind speeds (i.e., outside the hurricane eyewall) can be assessed with the Simple set-up. As with the Complex set-up, the Simple set-up data are provided at high resolution (every timestep) over a small grid at a radius of interest (Table 1), see in Fig. 2. The hurricane-like profiles simulated by the Simple set-up are analogous to observations from virtual towers at each location on the grid. 
The simulations discussed herein are summarized in Table 1. First, we compare simulations from the Complex and Simple set-ups at the same temporal and spatial resolution, as denoted by C62 and S62, respectively in Table 1. This direct comparison employs an idealized simulation of a relatively small, but intense, hurricane, e.g., Hurricane Felix 2007.

Then, to compare with hurricane observations, we ran the Simple set-up at a significantly higher spatial and temporal resolution $(\Delta x=10 \mathrm{~m}, \Delta t=0.1 \mathrm{~s})$, denoted by $\mathrm{S} 10$ in Table 1 . Data from the first case, at a radius of $130 \mathrm{~km}$, are compared to observations collected in Hurricane Isabel (2003), as described in Sect. 2.2. Further simulations with $\Delta x=10 \mathrm{~m}$ and $\Delta t=0.1 \mathrm{~s}$ at two additional radii, 35 and $70 \mathrm{~km}$, are used to evaluate variations of the power spectral density and coherence as a function of hurricane radius or, essentially, for different mean wind speeds (since wind speed increases as the radius decreases outside of the eye of a given hurricane). For all S10 simulations, high-resolution data over a $21 \times 21$ grid $(200 \mathrm{~m} \times 200 \mathrm{~m})$ from the centre of the domain allows calculation of power spectral density at high frequencies to estimate spatial coherence across the turbine rotor layer.

Finally, to compare directly with aircraft observations, data from the S10 simulation at a radius of $130 \mathrm{~km}$ were extracted along a fictitious aircraft track moving through space every timestep in a straight line through the Simple set-up domain. This approach allows for a fair comparison of the aircraft observations and model results, and ensures that analyzed gust frequencies are consistent in the two datasets. To allow for calculations of mean conditions and variations, we simulated 21 different flights, each separated by $250 \mathrm{~m}$ in the model domain, from this simulation denoted as SF10 in Table 1.

\subsection{Observations}

Both the Complex and Simple set-ups have been evaluated in other studies (e.g., Richter et al. 2016; Bryan et al. 2017). To test the suitability of the Simple set-up to represent turbulent flow in hurricanes, we compare data from the Simple set-up to the limited observational data available at turbine height and taken at suitable temporal resolution for power-spectral-density estimates. The sample time series comprises approximately 6 min of velocity observations (Fig. 3) collected during the Coupled Boundary Layer Air-Sea Transfer (CBLAST) - Hurricane experiment (Black et al. 2007; Zhang et al. 2009; Zhang 2010a). The length of this dataset is one-of-a-kind, because the other CBLAST measurements were taken for a duration of $3 \mathrm{~min}$ or less. The data were collected by the NOAA WP-3D Orion aircraft at a temporal resolution of $40 \mathrm{~Hz}$ at $194 \mathrm{~m}$ above the surface on 12 September 2003 inside Hurricane Isabel, with the storm at Category-5 intensity. The data were collected nearly $130 \mathrm{~km}$ away from the storm centre, and at this location, the near-surface wind speeds were of tropical storm intensity and no rainbands were present. The virtual tower and mock flights at a radius of $130 \mathrm{~km}$ described in Sect. 2.1.2 were designed to simulate the conditions under which these observations were obtained.

\section{Analysis Methods}

\subsection{Power Spectral Density}

To prepare the data and calculate power spectral density, several data processing steps are required. First, the components of the wind velocity are converted to streamwise (alongwind), cross-stream (cross-wind), and vertical components. Hereafter, $u, v$, and $w$, are used interchangeably with the above velocity-component definitions. Then, to smooth the spec- 


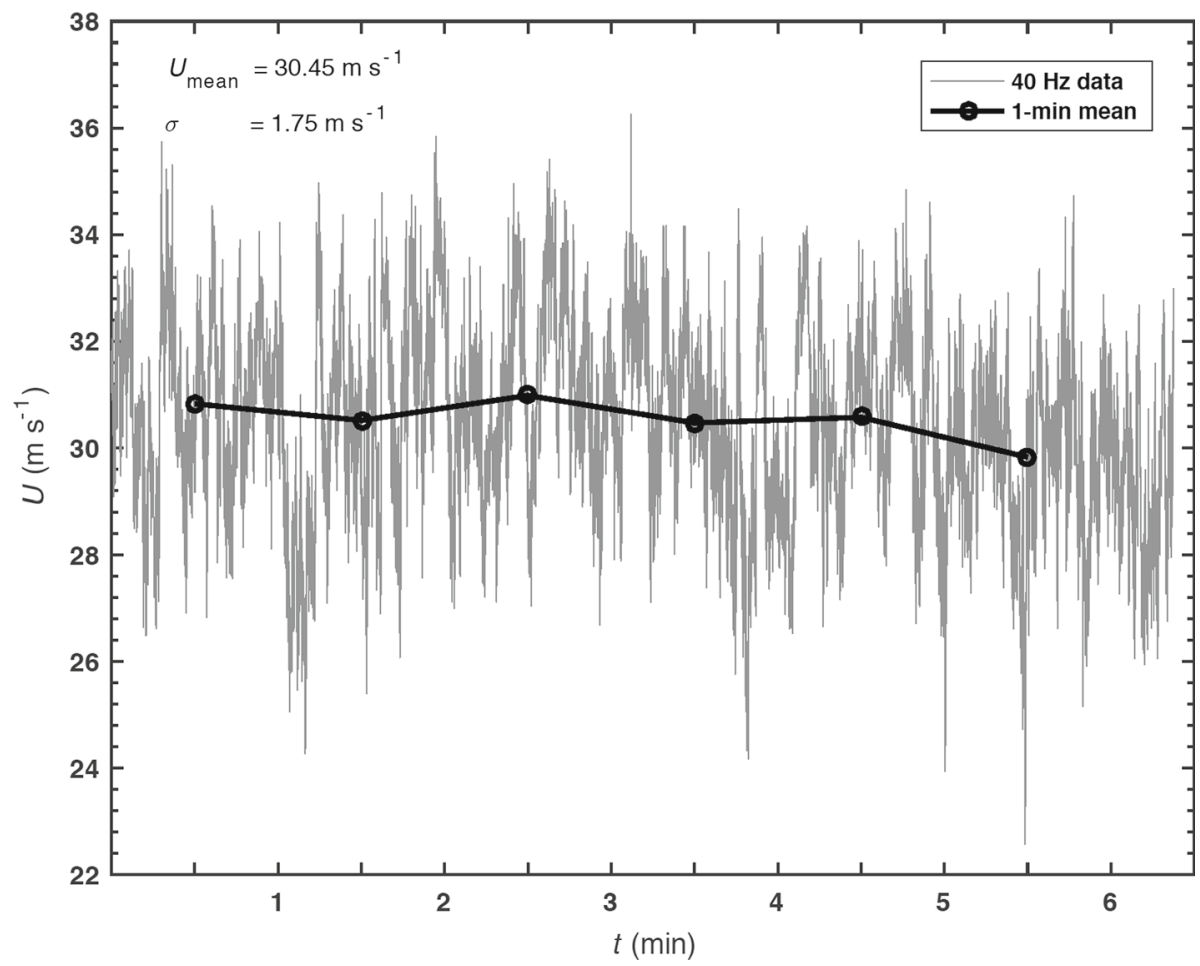

Fig. 3 Instantaneous (grey) and 1-min average (black) time series of the total horizontal wind speed collected during Hurricane Isabel on 12 September 2003 around 1800 UTC. The standard deviation and mean wind speeds were calculated from the complete time series. Data were collected during the CBLAST experiment at an altitude of $194 \mathrm{~m}$ and at a hurricane radius of $130 \mathrm{~km}$

trum and reduce bias, an ensemble average of $50 \%$ overlapping, equal-length segments of power spectral density is calculated. The ensemble average consists of 39 samples derived from $2 \mathrm{~h}$ of simulation. A 6-min segment of the time series is used here to match the duration of the CBLAST observations. After removing any linear trend, a window function is applied to minimize edge effects (i.e., sharp transitions in the signal) that result in spectral leakage (i.e., high side-lobes). The edge effects occur as artifacts of the underlying periodic assumption of the fast Fourier transform. A Blackman-Harris window function is used, which is a generalization of the Hamming window function that further minimizes side-lobes (Harris 1978).

When the turbulence spectrum in the atmosphere is considered for wind loads, standard spectral models are frequently used. Common spectral models include the empirical Kaimal model (based on observations in a neutrally-stratified PBL, Kaimal et al. 1972) and the theoretical isotropic von Kármán model (assuming homogeneous and isotropic turbulence) (von Kármán and Lin 1951). On average, the HBL is neutrally stable (Powell et al. 2003; Vickery and Skerlj 2005) except at its top (Zhang et al. 2011; Kepert et al. 2015), which is well above turbine-hub height, allowing for comparison with these traditional models.

The IEC 61400-1 (IEC 2007) standard for the streamwise Kaimal model (Eq. 1), incorporates a constant integral scale parameter, $L_{u}$, equal to $340 \mathrm{~m}$ for hub heights $>60 \mathrm{~m}$, and a standard deviation of the horizontal wind speed at hub height, $\sigma$, 


$$
S_{\mathrm{u}}(f)=\frac{\frac{a \sigma^{2} L_{\mathrm{u}}}{V_{\mathrm{hub}}}}{\left(b+c\left(\frac{f L_{\mathrm{u}}}{V_{\mathrm{hub}}}\right)\right)^{\frac{5}{3}}},
$$

where $a, b$, and $c$ are coefficients equal to 4,1 , and 6 , respectively. $V_{\text {hub }}$ is the mean horizontal wind speed at hub height and $f$ is the frequency.

The isotropic von Kármán model (Eq. 2) parameters are the integral scale parameter $L_{\mathrm{vk}}$, mean horizontal wind speed at hub height $V_{\text {hub }}$, frequency $f$, and variance of the wind speed at hub height $\sigma^{2}$. The integral scale parameter $L_{\mathrm{vk}}$, is set to the IEC standard value of $147 \mathrm{~m}$ for hub heights $>60 \mathrm{~m}$,

$$
S_{\mathrm{u}}(f)=\frac{a \sigma^{2} L_{\mathrm{vk}} / V_{\mathrm{hub}}}{\left(b+c\left(\frac{f L_{\mathrm{vk}}}{V_{\mathrm{hub}}}\right)^{2}\right)^{\frac{5}{6}}},
$$

where $a, b$, and $c$ are coefficients equal to 4,1 , and 71 , respectively.

\subsection{Spectral Coherence}

Spectral coherence (Eq. 3) is a function of frequency with a value between zero and one, indicating how well two spatially-separated time series are correlated. The square of the cross-power spectral density $(C P S D)$ function between two time series, separated by some distance, is normalized by the product of the auto-power spectral densities (PSD) of each of the two time series $x_{1}$ and $x_{2}$ (Larsen and Hansen 2004; Saranyasoontorn et al. 2004),

$$
\operatorname{Coh}(f)^{2}=\frac{\left|C P S D_{x 1 x 2}(f)\right|^{2}}{P S D_{x 1}(f) P S D_{x 2}(f)},
$$

where $f$ is frequency in Hertz and $x$ can be the $u, v$, or $w$ velocity component of the flow. Each velocity component is treated separately. For example, if $x_{1}$ is the streamwise component at one location, $x_{2}$ is the streamwise component at a different location; two different windvelocity components are not included in the same calculation of $\operatorname{Coh}(f)^{2}$.

For the S10 simulations, coherence is calculated in a $21 \times 21$ grid centred at the location of a theoretical offshore turbine with the dimensions of the NREL 5-MW reference wind turbine (Jonkman et al. 2009). This turbine is a three-bladed, upwind turbine with a hub height of $90 \mathrm{~m}$ and rotor diameter of $126 \mathrm{~m}$. Since the model does not directly represent turbines, the analysis is based on what the power spectral density and coherence would be if the turbine were in place (i.e., flow at hub height and across the rotor layer). The coherence calculations capture the turbulent flow experienced by the turbine in the rotor-swept area but do not consider downwind wake effects. A model of the wind turbine itself, such as in Mirocha et al. (2014) and Aitken et al. (2014), would be required to consider wake effects. Coherence calculated across various lengths of the turbine structure is examined below.

The commonly-used empirical model for horizontal and vertical separations of coherence is the IEC exponential coherence model (Thresher et al. 1981; IEC 2007),

$$
\operatorname{Coh}(f)^{2}=\left(\exp \left[-a \sqrt{\left(\frac{f S}{V_{\mathrm{hub}}}\right)^{2}+\left(\frac{b S}{L_{\mathrm{c}}}\right)^{2}}\right]\right)^{2},
$$


where $L_{\mathrm{c}}$ is the coherence scale parameter, specified by the IEC as $340 \mathrm{~m}$ for wind turbines with a hub height $>60 \mathrm{~m}, S$ is the spatial separation between two points of interest along the turbine, $f$ is frequency, and $V_{\text {hub }}$ is the mean horizontal wind speed at hub height. The coefficients $a$ and $b$ are equal to 12 and 0.12 , respectively, according to the IEC standard.

\section{Results}

\subsection{Comparison Between Complex and Simple Set-ups}

Because the Complex set-up simulates all aspects of a hurricane (including the eye and eyewall) and includes moisture, it would ideally be used for all analyses in our study. However, the Complex set-up is two orders of magnitude more computationally expensive than the Simple set-up, which limits the resolution in practice $(\Delta x=62.5, \Delta z=31.25 \mathrm{~m}, \Delta t=$ $0.375 \mathrm{~s}$ herein). Therefore, the bulk of our analysis below uses the Simple set-up to allow for higher-resolution simulations ( $\Delta x=10 \mathrm{~m}, \Delta z=5 \mathrm{~m}, \Delta t=0.1 \mathrm{~s}$ ) and also allows for larger radii than the Complex set-up (for which the fine-mesh domain spans only $80 \mathrm{~km} \times 80 \mathrm{~km}$ ). To establish the utility of the Simple set-up to represent the complex nature of wind conditions in a full hurricane, we first compare wind speed, variance, and power spectra from a Simple set-up simulation to those of a Complex set-up simulation (i.e., C62 and S62 simulations as listed in Table 1).

Normalized average total horizontal wind speed and total horizontal variance for both C62 and S62 simulations are compared at three radii of the modelled hurricane (Fig. 4). Normalized wind-speed and variance profiles from the Simple set-up simulation compare favourably to those in the Complex set-up simulation at $25 \mathrm{~km}$ (Fig. 4a, d) and $30 \mathrm{~km}$ (Fig. 4b, e), in the sense that the shape of the wind-speed profiles is similar and the wind speed and variance are within $15 \%$ at all heights. At a radius of $35 \mathrm{~km}$ (Fig. 4c, f), the S62 wind speeds are consistently less than those in the C62 wind profiles, by as much as $46 \%$, although data from the Simple set-up are very sensitive to model parameters (see Sect 3.2 of Bryan et al. 2017), suggesting that the parameters for the S62 simulation could be better "tuned" to match the C62 case. In all cases shown in Fig. 4, differences in the mean wind speed increase with height, while differences in the variance are largest between 50 and 150 $\mathrm{m}$. These differences in variance suggest differences in the power spectral density, although we have not found any significant differences between the power spectra in the two set-ups (Fig. 5).

The dominant length scales associated with the normalized frequency at the peak magnitude of the normalized spectra are similar between the two set-ups. The dominant length scale is $\approx 3,2$, and $3.5 \mathrm{~km}$ at 50,100 , and $200 \mathrm{~m}$ a.s.1., respectively for the Simple set-up; for the Complex set-up, the dominant length scales are $\approx 1.5,1$, and $3 \mathrm{~km}$ for the same altitudes. The mean wind speed at the radius shown in Fig. 5 (i.e., $R=20 \mathrm{~km}$ ) is roughly $2-3 \mathrm{~m} \mathrm{~s}^{-1}$ greater in the Simple set-up than in the Complex set-up, which contributes to the slightly larger length scales in the Simple set-up than in the Complex set-up.

Comparisons between normalized power spectral density from the S62 and C62 simulations at three different altitudes relevant to the theoretical turbine also show good agreement in magnitude and shape; the average percentage difference between the two spectra is $<1 \%$ for each altitude (Fig. 5). Spectra from both set-ups agree well at all altitudes; both follow the Kolmogorov $-5 / 3$ power law in the inertial subrange (beginning at a normalized frequency 

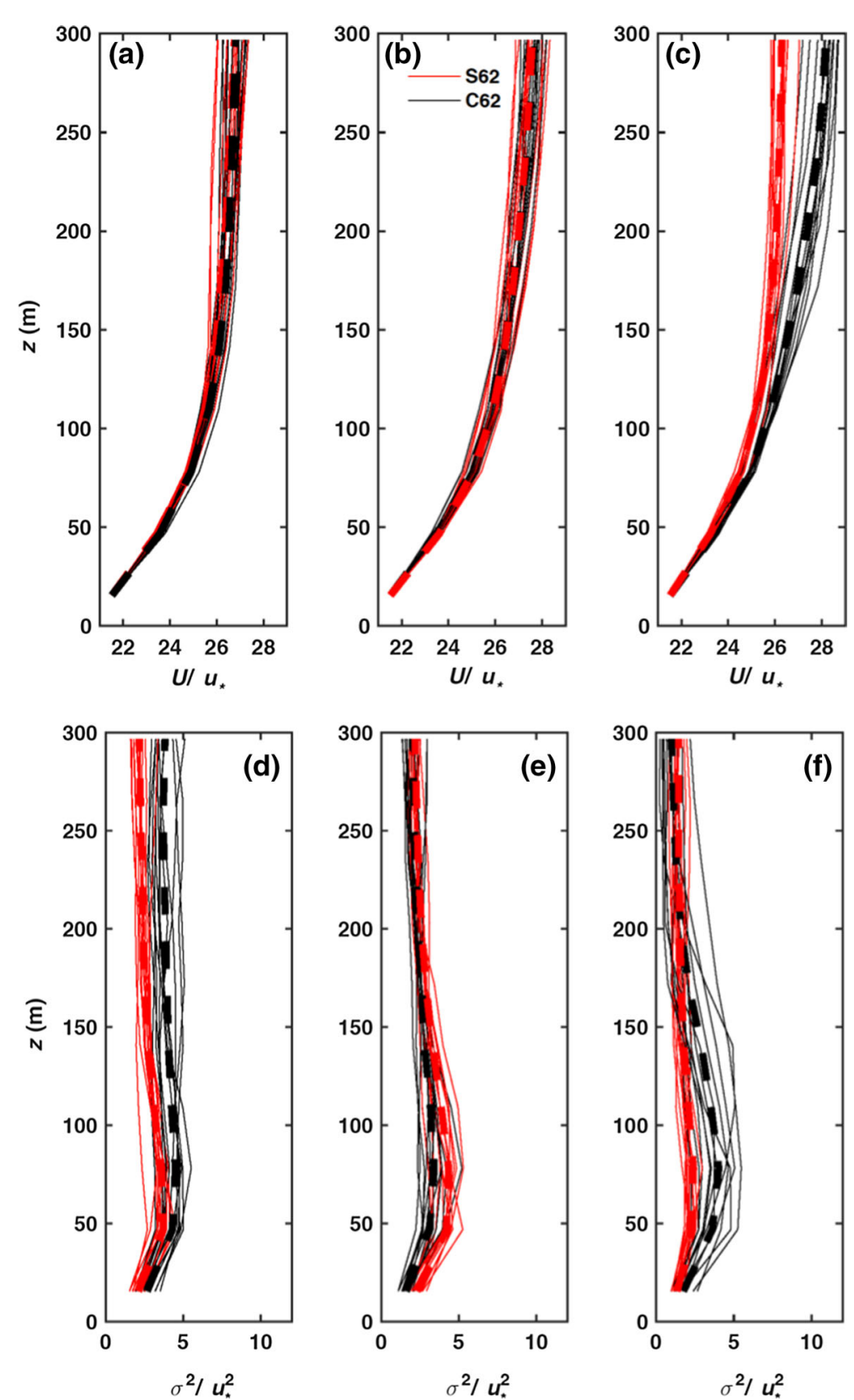

Fig. 4 Profiles of the average total horizontal wind speed for C62 (black) and S62 (red) simulations at radii of, a $25 \mathrm{~km}$, b $30 \mathrm{~km}$, and c $35 \mathrm{~km}$ normalized by friction velocity, $u_{*}$. Profiles of the normalized average resolved-scale variance of the total horizontal wind speed at radii of, $\mathbf{d} 25 \mathrm{~km}$, e $30 \mathrm{~km}$, and $\mathbf{f} 35 \mathrm{~km}$ are also shown. Thick, dashed lines are 2-h averages while thin, solid lines are 10-min averages 


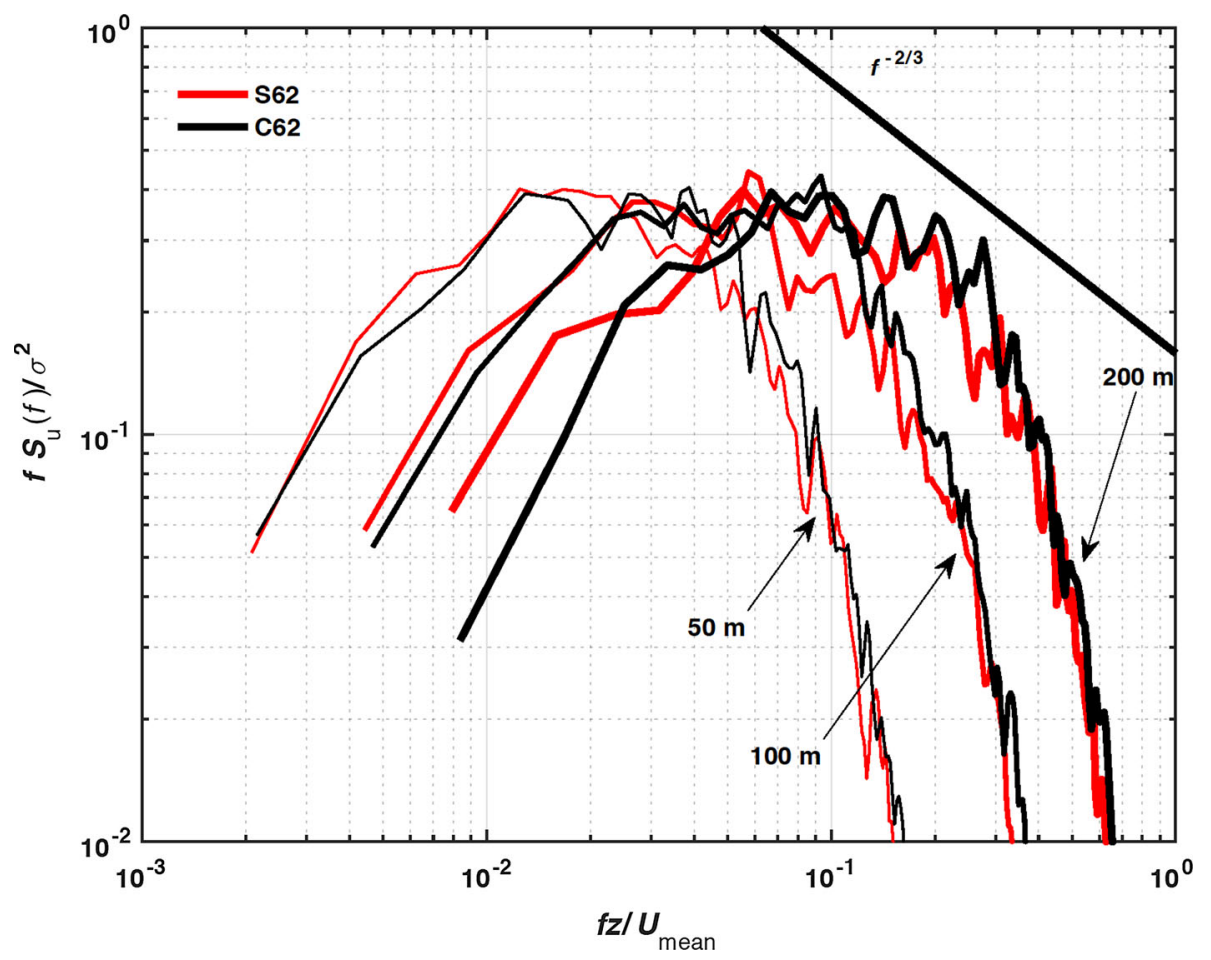

Fig. 5 Normalized power spectral density of the streamwise velocity component from S62 (red) and C62 (black) simulations at a hurricane radius of $20 \mathrm{~km}$ and at three different altitudes pertinent to wind-turbine heights $(50,100$, and $200 \mathrm{~m})$

of $\approx 0.03,0.1$, and 0.2 for an altitude of 50,100, and $200 \mathrm{~m}$ a.s.1., respectively) with a rapid drop-off at higher frequencies due to the model's numerical schemes (e.g., Bryan et al. 2017).

To resolve higher frequencies (smaller wavelengths), the spatial and temporal resolutions need to be increased, and the ability to use increased resolution is the main advantage of the the Simple set-up. Results in this section demonstrate that the Simple set-up produces qualitatively similar wind-speed and variance profiles as the Complex set-up (Fig. 4), and yields very similar spectra (Fig. 5), providing confidence that the Simple set-up faithfully represents turbulent conditions in more complex hurricane simulations.

\subsection{Simple Set-up Simulations Compared to Hurricane Observations}

To further evaluate the Simple set-up, we now compare simulations with hurricane observations collected at a hurricane radius of $130 \mathrm{~km}$. Extended best-track hurricane wind-speed and radius data (Demuth et al. 2006) and analyses performed by Zhang and Drennan (their Fig. 2b, 2012) of Hurricane Isabel (2003) helped us determine appropriate model parameters (Table 2) for the Simple set-up simulation, for comparison to the CBLAST observations of Hurricane Isabel. The mean horizontal wind speed and standard deviation from 21 mock flights through the Simple set-up domain are 30 and $1.6 \mathrm{~m} \mathrm{~s}^{-1}$ respectively, values that are within $1 \mathrm{~m} \mathrm{~s}^{-1}$ of those calculated for the CBLAST observations (see Fig. 3). The spectra from the CBLAST observations and from the 21 mock flights detailed in Sect. 2.1.2 are 
Table 2 Model parameters for the Simple set-up simulations of Hurricane Isabel (2003)

\begin{tabular}{llllrr}
\hline Simulation & $f\left(\mathrm{~s}^{-1}\right)$ & $V\left(\mathrm{~m} \mathrm{~s}^{-1}\right)$ & $R(\mathrm{~km})$ & $\mathrm{d} V / \mathrm{d} R\left(\mathrm{~s}^{-1}\right)$ & $w_{\mathrm{min}}\left(\mathrm{m} \mathrm{s}^{-1}\right)$ \\
\hline SF10, TS & $5 \times 10^{-5}$ & 37 & 130 & $2 \times 10^{-4}$ & $-1.0 \times 10^{-2}$ \\
S10, TS & $5 \times 10^{-5}$ & 37 & 130 & $-2 \times 10^{-4}$ & $-1.0 \times 10^{-2}$ \\
S10, Cat 2 & $5 \times 10^{-5}$ & 72 & 30 & $-8.2 \times 10^{-4}$ & $-2.5 \times 10^{-2}$ \\
S10, Cat 4 & $5 \times 10^{-5}$ & 90 & 35 & $2 \times 10^{-3}$ & $-5.0 \times 10^{-2}$ \\
\hline
\end{tabular}

The SF10 mock flights were directly compared to CBLAST flight observations of Hurricane Isabel at 1800 UTC 12 September 2003. The mock flights were flown into the mean wind direction (south-south-east) with a fixed ground speed of $140 \mathrm{~m} \mathrm{~s}^{-1}$, the mean wind speed of the P3 aircraft that collected data during the CBLAST experiment

smoothed to better explore agreement between the observations and simulated results. We block-average the spectra using 100 equally-spaced, non-overlapping bins of the logarithm of the frequency (Blackman and Tukey 1959; Piper and Lundquist 2004).

The comparison of the power spectral density for each velocity component calculated from CBLAST observations and that from the mock flights from the Simple set-up exhibits good agreement (Fig. 6). For the streamwise and vertical velocity components, the observations fall within the bounds of the minimum and maximum power spectral density for all 21 mock flights denoted by the light-blue shaded region in Fig. 6. The average vertical power-spectral-density curve from the model follows the observations remarkably well at frequencies below $2 \mathrm{~Hz}$. For the cross-stream component, the model mock flights do not match the power spectral density from observations for frequencies $<0.02 \mathrm{~Hz}$. This discrepancy may arise because the observations are from one flight only and one time series, and a flight that may have sampled a mesoscale velocity fluctuation that cannot be represented in the Simple set-up, e.g., as related to rainbands. Also, with more data, the observed power spectral density of the cross-stream component may align with the simulated "flights". Nonetheless, for all components, the Simple set-up produces a realistic inertial subrange (i.e., the range of frequencies where turbulence energy is neither produced nor dissipated, but rather transported to smaller scales). Both power-spectral-density curves from the HBL observations and simulations vary according to the Kolmogorov power law, $f^{-5 / 3}$, in the inertial subrange. The simulated spectra for all velocity components begin to deviate from the Kolmogorov power law for frequencies $>2 \mathrm{~Hz}$, as expected from LES (which does not simulate all scales of a turbulent flow). The details of the "drop-off" in power are related to the model's numerical methods, which affect scales $<6 \Delta x$ in the model (e.g., Bryan et al. 2003). In this case, the drop-off begins at roughly $2 \mathrm{~Hz}$, corresponding to a frequency $f=u_{\mathrm{a}} /(6 \Delta x)$, where $u_{\mathrm{a}}=120 \mathrm{~m} \mathrm{~s}^{-1}$ corresponds roughly to the airspeed of the mock airplanes.

This agreement in the shape, magnitude, and inertial subrange of the power-spectraldensity curve of the model data suggests that the Simple set-up produces realistic turbulent fluctuations in hurricanes, and thus model data can be used further to investigate coherence inside the HBL, where adequate observations to calculate coherence are unavailable. Subsequent analysis is performed with the $\mathrm{S} 10$ simulation data, using stationary virtual towers.

\subsection{Comparison of LES-Derived Power Spectral Density to Established Spectra}

The power spectral density from the Simple set-up can be compared to the Kaimal and von Kármán spectra detailed in Sect. 3.1. For this comparison, the variables $V_{\text {hub }}$ and $\sigma^{2}$ for the Kaimal (Eq. 1) and von Kármán (Eq. 2) spectral models were calculated using a 2-h mean of 
Fig. 6 Comparison of power spectral density between the SF10 simulation (blue line) at 194 m altitude and the CBLAST observations (black line) at $194 \mathrm{~m}$ altitude at a radius of $130 \mathrm{~km}$ from the storm centre. The streamwise power spectral density is shown in (a), the cross-stream in (b), and the vertical power spectral density in (c). The dark blue line is the average power spectral density calculated from 21 mock flights, the medium-blue-shaded region represents the interquartile range and the light-shaded region represents the maximum and minimum of all 21 power spectral densities
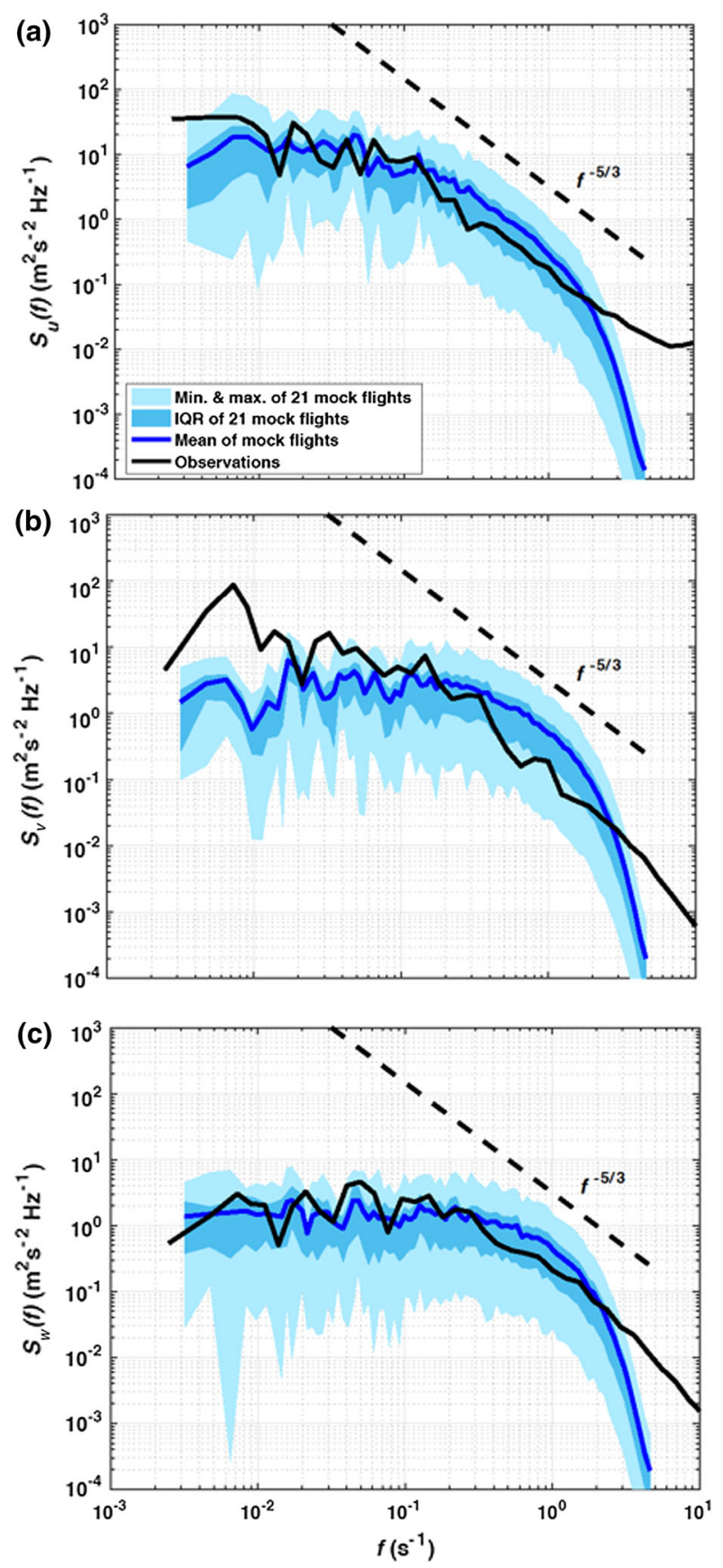

the horizontal wind speed produced from the entire time series of the $\mathrm{S} 10$ simulations at $100 \mathrm{~m}$ a.s.l. (near hub height for the NREL 5-MW turbine). The empirical and theoretical spectra are then compared to the three S10 power-spectral-density curves representing mean wind speeds corresponding to a tropical storm $(R=130 \mathrm{~km})$, a Category- 2 condition $(R=70 \mathrm{~km})$, and a 
Fig. 7 Normalized power spectral density of the streamwise velocity component at an altitude of $100 \mathrm{~m}$ for the, a TS, b Category-2, and c Category-4 cases. The normalized average power spectral density from the Simple set-up at $10 \mathrm{~m}$ horizontal grid spacing (blue), Kaimal model (purple), von Kármán model (cyan), the best-fit line of the power spectrum from the Simple set-up (black-solid) for each storm intensity, and the general power-spectral-density fit (red) are shown. The

Kolmogorov power law

(black-dashed) is also shown to reveal the inertial subrange. The mean wind speed at $10 \mathrm{~m}$ a.s.1. for each case is also displayed
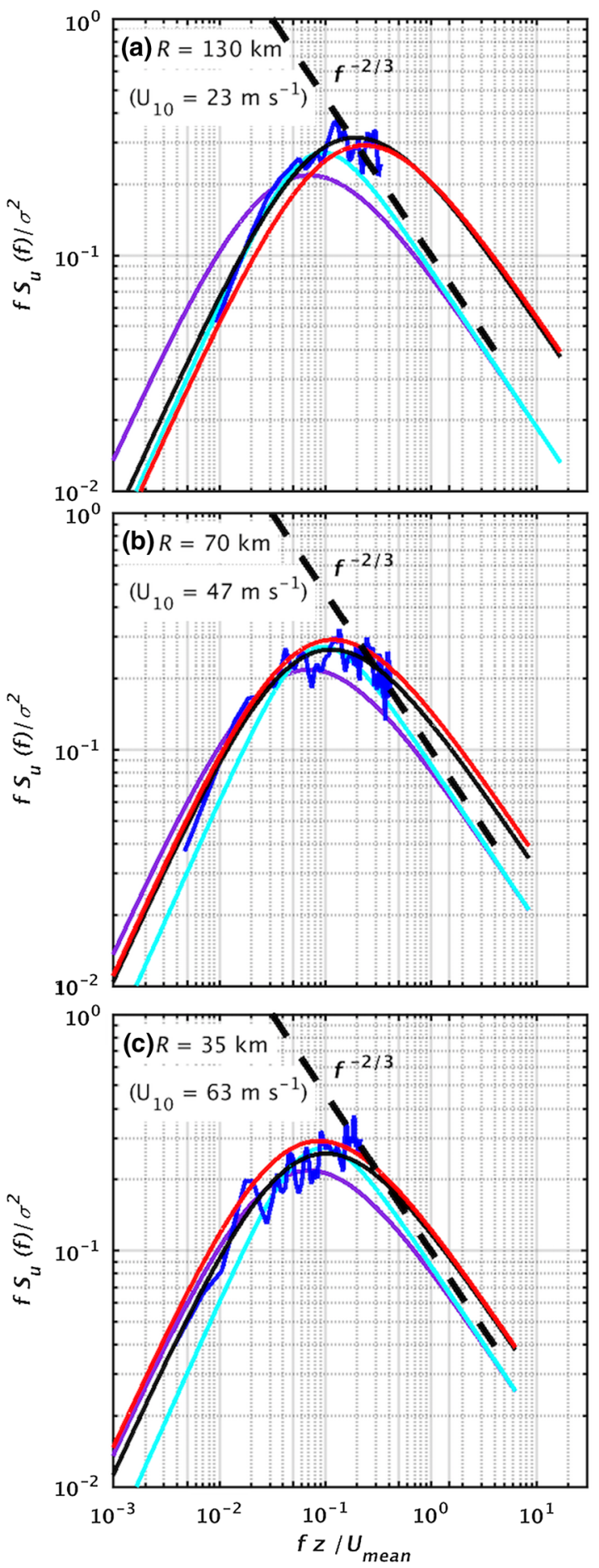
Category-4 condition ( $R=35 \mathrm{~km})$ (Fig. 7). Because the Kaimal and von Kármán models are provided $V_{\text {hub }}$ and $\sigma^{2}$ from the Simple set-up, the spectral models should match the powerspectral-density curves from the S10 simulations if the spectral models represent turbulence characteristics of the HBL.

Both the Kaimal and von Kármán spectral curves slightly underestimate the power spectral density at most frequencies (Fig. 7). Analyses at other altitudes (not shown) show the same result, up to at least $200 \mathrm{~m}$ a.s.l. These differences may occur because the wind conditions in the HBL are more variable than in the onshore, neutral PBL from which these curves were derived. This result is consistent with onshore-hurricane observations (Yu et al. 2008). Yu et al. (2008) found that the magnitude of the streamwise power spectral density of flow from the sea was greater than the power spectral density of flow originating over open terrain based on tower measurements $5 \mathrm{~m}$ and $10 \mathrm{~m}$ above the surface. However, the increased magnitude of the power-spectral-density curve in the sea-to-land case in Yu et al. (2008) could be attributed to increased turbulence energy induced by waves breaking and shoaling on approach to the coastline.

The greatest difference between the simulated spectra and the theoretical curves occurs in the inertial subrange, where the spectral magnitude decreases according to Kolmogorov's theory (shown as the dashed-black lines in Fig. 7). The power in the inertial subrange of the simulated spectrum is also approximately two times greater than that in the observed spectrum for the tropical storm case. This increase in energy for the simulated flow in the inertial region implies that the rate of TKE dissipation $\varepsilon$ and the friction velocity $u_{*}$ are high (i.e., $u_{*}$ ranges between 1 and $3 \mathrm{~m} \mathrm{~s}^{-1}$ ). However, $u_{*}$ calculated from the TKE dissipation within the inertial subrange for each case according to Eqs. 5 and 6 is consistent with $u_{*}$ calculated from the turbulence parametrization scheme

$$
\varepsilon=\alpha_{\mathrm{u}}^{-\frac{3}{2}} 2 \pi f U^{-1}\left[f S_{\mathrm{u}}(f)\right]^{\frac{3}{2}},
$$

where $U$ is the mean wind speed, $S_{\mathrm{u}}$ is the streamwise power spectral density, $f$ is the frequency, and $\alpha_{\mathrm{u}}$ is the one-dimensional Kolmogorov constant $(=0.53)$ for the streamwise component, versus

$$
u_{*}^{3}=\varepsilon \kappa z
$$

where $z$ is the altitude and $\kappa$ is the von Kármán constant $(=0.4)$.

For the tropical storm case (Fig. 7a), $u_{*}$ calculated from the spectra is $1.08 \mathrm{~m} \mathrm{~s}^{-1}$ and $u_{*}$ from the turbulence scheme is $1.06 \mathrm{~m} \mathrm{~s}^{-1}$. Similar results between the calculated $u_{*}$ and the model $u_{*}$ were also found for the other two cases: $\approx 2 \mathrm{~m} \mathrm{~s}^{-1}$ for the Category- 2 case and $3 \mathrm{~m} \mathrm{~s}^{-1}$ for the Category- 4 case. These $u_{*}$ values are consistent with recent observations (Andreas et al. 2012; Bell et al. 2012). Additionally, increases in $u_{*}$ (and $\varepsilon$ ) with hurricane wind speed have been observed (Zhang 2010b). These results provide confidence that the larger magnitudes of power spectral density within the inertial subrange of the simulated data are reliable.

Compared to the Kaimal and von Kármán curves, the frequency of peak power in the S10 power-spectral-density curves is also shifted to higher frequencies for all three storm examples, in agreement with Zhang (2010a). The normalized frequency of the peak powerspectral-density curve for all storm examples (blue lines in Fig. 7) is approximately 1.5 to three times greater than that for the Kaimal curve and up to 2.5 times greater than for the von Kármán curve. This shift suggests that eddies that contribute to the most turbulence energy in the HBL are of a smaller wavelength than in non-hurricane conditions where the empirical and theoretical curves apply. 
Table 3 Coefficients for the Kaimal spectra (Eq. 1) as they are defined in the IEC standard, and as calculated from LES of three different hurricane intensities

\begin{tabular}{llllll}
\hline & IEC & TS & Category-2 & Category-4 & Recommended \\
\hline$a$ & 4 & 11 & 6.7 & 6 & 8.7 \\
$b$ & 1 & 2.7 & 1.6 & 2 & 2 \\
$c$ & 6 & 6 & 6 & 6 & 6 \\
\hline
\end{tabular}

The recommended coefficients, based on a general fit for a range of tropical storm (TS) and hurricane intensities, are also shown

Therefore, adjustments can be made to these spectral models to better represent the turbulent nature of the HBL. To account for the greater magnitude of power spectral density at most frequencies, and the shift in peak power to higher frequencies in the HBL, the new suggested spectral model follows the general structure of the Kaimal relation (Eq. 1), but with modified coefficients. We estimated the coefficients for each storm category (Table 3 ) by iterative least-squares estimation of a non-linear regression, given initial values corresponding to the selected coefficients used in Eq. 1 (described below) and fitting only for normalized frequencies from 0.005 to $\approx 0.35$ (because the LES model inherently loses power at higher frequencies).

Since the power-spectral-density curves from the S10 simulation (Fig. 7) are larger in magnitude than the Kaimal curve, except at normalized frequencies $<10^{-1} \mathrm{~Hz}$ in the tropical storm case, and the peak frequency is also offset from that of the Kaimal curve, we only need to adjust the coefficients that affect the magnitude and location of the peak of the spectrum. For the Kaimal equation, the coefficient $a$ in Eq. 1 controls the magnitude of the spectrum; an increase in the coefficient produces an increase in the spectrum magnitude at all frequencies. The coefficient, $b$ in Eq. 1, controls the location of the peak frequency; an increase causes the peak energy of the spectrum to shift to higher frequencies. The final coefficient, $c$ in Eq. 1, has the same effect as coefficient $b$, but an increase in coefficient $c$ results in a shift of the peak energy to lower frequencies. Here, we chose to determine the best-fit for coefficients $a$ and $b$ while maintaining coefficient $c$ the same as that used in Eq. 1.

The same values for $V_{\text {hub }}$ and $\sigma^{2}$ used in Eq. 1 were used in the regression analyses for each corresponding hurricane case; the values were calculated from the entire time series, and so truncation did not affect these values. We tested different length scales ranging from 180 to $450 \mathrm{~m}$, which are observed hurricane length scales (Yu et al. 2008). We did not see any notable differences in the non-linear fits, so we chose to keep the length scale the same as that used in the IEC standard, $340 \mathrm{~m}$, which also falls within the range of length scales reported by Yu et al. (2008). The non-linear fits (black curves in Fig. 7a-c) follow the normalized power spectrum of the HBL while providing simple adjustments to the commonly-used Kaimal spectrum that can be implemented in a straight-forward way in wind-field simulators.

Based on the coefficients in Table 3, we note that the power spectral density is most different for the tropical storm case compared to the IEC Kaimal coefficients, and also when the tropical storm case is compared to the other two cases. The coefficients derived from the non-linear regression for the Category- 2 and Category- 4 cases are essentially the same, suggesting similar turbulence characteristics for hurricanes spanning Categories 2-4. Tests for load models such as TURBSIM would have to be conducted to determine if the coefficients in the tropical storm case differ enough to produce significant variations in the overall turbulence intensities compared to the coefficients used in the Category- 2 and -4 cases. Slightly better fits are achieved with wind-speed-specific parameters, but for general 
application, we suggest using the coefficients in the "Recommended" column in Table 3 for the modified power spectral density, as these coefficients were determined from a non-linear regression using all three storm categories (shown as the red curves in Fig. 7). For all storm categories, the root-mean-square errors calculated between the simulated HBL spectra and the Kaimal spectra were reduced by $\approx 42-63 \%$ by using the coefficients in the "Recommended" column in Table 3 instead of the IEC coefficients for the Kaimal curve. Similar results were found for altitudes of $50 \mathrm{~m}$ and $200 \mathrm{~m}$ a.s.1. (not shown).

\subsection{Flow Variability in the HBL}

To explore the variability of streamwise power spectral density in the HBL at different hurricane radii (or, essentially, for different mean wind speeds in a given hurricane), we highlight features of the power spectral density as a function of altitude and frequency (Fig. 8). In the HBL, as simulated here, the peak magnitude of the power spectral density occurs at altitudes $<100 \mathrm{~m}$ (Fig. 8) for all three storm intensities. Recall that the NREL 5-MW turbinehub height is $90 \mathrm{~m}$ and the rotor layer spans altitudes from 15 to $165 \mathrm{~m}$. Thus, dominant energy in the flow occurs at lower reaches of the turbine, which might lead to increased loading at the base of the tower and outer part of the blades via bending.

Additionally, the peak of the power spectral density shifts to higher frequencies as radius decreases. In other words, higher frequency structures dominate the energy in the turbulent flow as one moves closer to the hurricane eyewall. A dependence of peak power spectral density on hurricane intensity is also visible as a function of altitude: as the radius decreases (i.e., wind speed increases, excluding the eye), the vertical extent of the peak power increases. The Category- 4 case shows that the location of the peak power (yellow contours in Fig. 8) in the flow exceeds $150 \mathrm{~m}$ a.s.l., potentially causing significant loading across the entire turbine.

When normalized by frequency and the variance of the streamwise velocity component (Fig. 8d-f), the peak power spans the entire vertical extent of the turbine at all radii shown. The dependence of the peak energy on frequency is also apparent. At radii closer to the eyewall (e.g., for higher wind speeds, Fig. 8e, f), the normalized frequencies that dominate the energy in the flow are higher (up to 0.4) than the contributing frequencies (up to 0.15) at the larger radii (e.g., tropical storm case). This result is consistent with the results shown for the non-normalized power spectral densities in Fig. 8a-c, which show that higher frequency features contribute larger proportions of energy to the turbulent flow near the eyewall than at large radii.

\subsection{Coherence in the HBL}

Because of the presence of boundary-layer rolls (Wurman and Winslow 1998; Nolan 2005) and the overall structure of hurricanes (e.g., eye, eyewall, rainbands), the HBL is inherently inhomogeneous. Turbulent flow in contact with an offshore wind turbine varies over different portions of the turbine, including the rotor-swept area. Analysis of coherence at points of interest on a turbine provides information on how turbulence within the HBL changes over the turbine structure, influencing loads such as bending moments. In addition, coherence is an essential component in three-dimensional wind-field simulators, because it describes how turbulence is correlated as a function of spatial separation. Although established models for coherence are codified in design standards (IEC 61400-1, IEC 2007), limited observational studies suggest that coherence is more widely variable than assumed in these standards (Saranyasoontorn et al. 2004). 

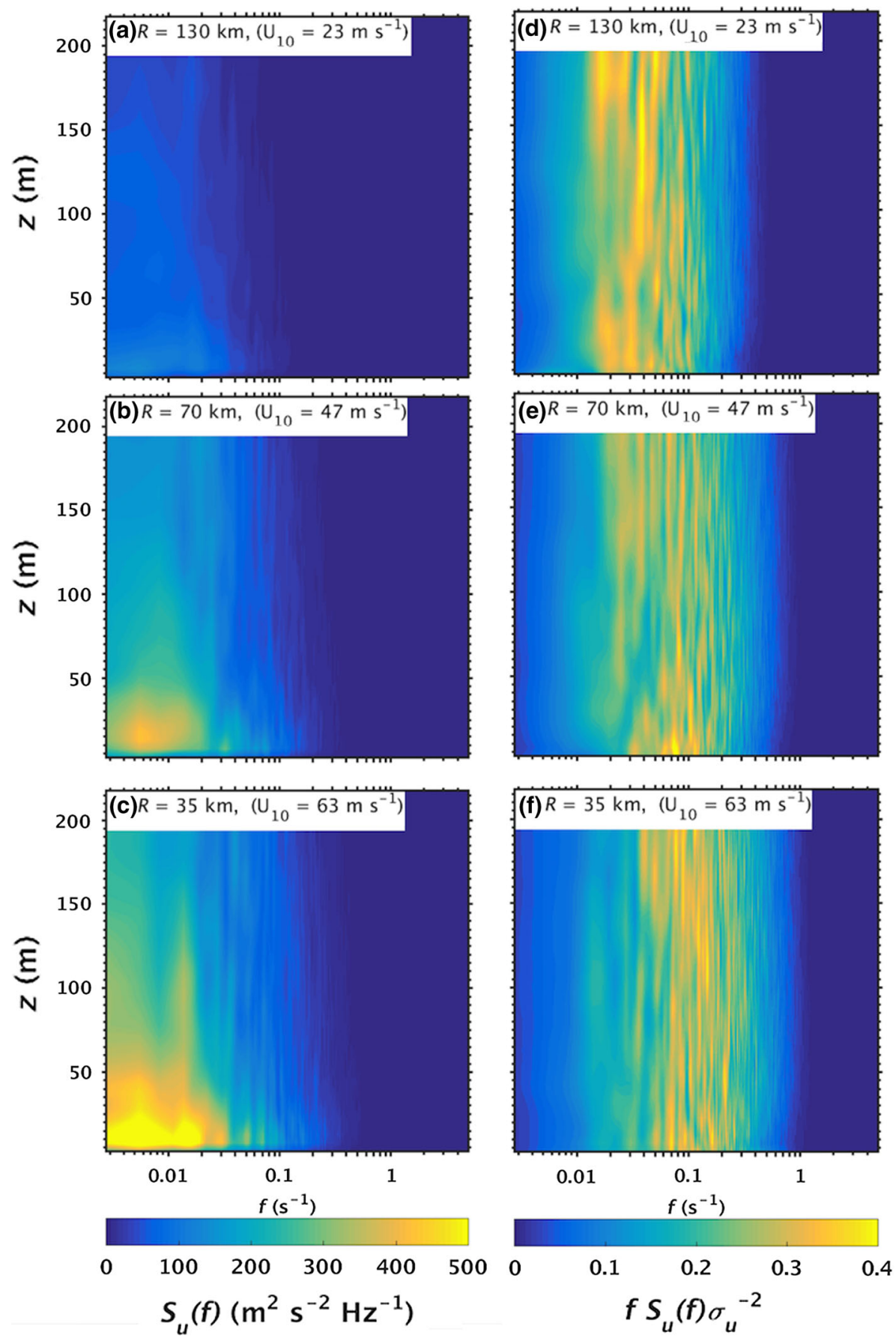

Fig. 8 Contours of the non-normalized (left column) and normalized (right column) power spectral density of the streamwise velocity component of the Simple set-up with a horizontal spacing of $10 \mathrm{~m}$. Three different hurricane radii are shown to represent tropical storm (a, d), Category-2 (b, e), and Category-4 (c, f) intensities. The mean wind speed at $10 \mathrm{~m}$ a.s.l. for each case is also displayed 
To assess the spatial coherence in the HBL, we calculate coherence across the $21 \times 21$ $(200 \mathrm{~m} \times 200 \mathrm{~m})$ subdomain of the $\mathrm{S} 10$ simulation. We assume that a theoretical turbine is located at the far downwind end of this domain so that coherence across the entire rotor layer can be calculated. Eddies within the flow that are approximately the length of the turbine blade and that exhibit high coherence across this length can produce increased damage-equivalent loads on turbine mechanical components.

Our simulations suggest that the HBL is highly coherent. At a radius of $130 \mathrm{~km}$ and horizontal separations of $10 \mathrm{~m}$ (Fig. 9a), the flow is highly coherent $(\geq 0.6)$ at all altitudes and at frequencies as high as $0.2 \mathrm{~Hz}$. For horizontal separations $<20 \mathrm{~m}$ (Fig. 9a-b), the flow is highly coherent at all altitudes $<210 \mathrm{~m}$ a.s.l. and for all frequencies $<0.05 \mathrm{~Hz}$. Therefore, at hub height, flow is highly coherent across at least one-third the length of the theoretical turbine blade $(\approx 63 \mathrm{~m})$ for a range of frequencies spanning two orders of magnitude. At $100 \mathrm{~m}$ a.s.1., separations as large as $40 \mathrm{~m}$ produce high coherence values for frequencies $<0.02 \mathrm{~Hz}$. Further, flow remains highly coherent at a wider range of frequencies at altitudes $>50 \mathrm{~m}$ compared to the flow closer to the surface. When designing offshore turbines for hurricaneprone regions, turbine designers should consider the possibility of smaller eddies existing near the foundation of the turbine and larger eddies existing near hub height.

Coherence in the HBL is not only a function of frequency and altitude, but also of hurricane intensity. At a radius of $70 \mathrm{~km}$ (Fig. 10) and $35 \mathrm{~km}$ (Fig. 11), corresponding to Category-2 and Category-4 wind speeds, respectively, the coherence is larger than that in the tropical storm case for all separations and frequencies (Fig. 9). The wind velocity in the HBL is so coherent in the strong hurricane cases that at $100 \mathrm{~m}$ a.s.l., the turbulence remains highly coherent $(\geq 0.6$ ) for separations as large as $60 \mathrm{~m}$ for frequencies as high as $0.05 \mathrm{~Hz}$ (Category-2 case) and $0.07 \mathrm{~Hz}$ (Category-4 case). This separation length is roughly the size of a typical turbine blade.

The increase in coherence from tropical storm intensity to that of a Category- 2 hurricane is more drastic than the increase in coherence from Category- 2 to Category- 4 intensity. This behaviour is consistent with the results in Table 3, which showed that the modified-Kaimal power-spectral-density curves fit to the Category- 2 and -4 cases were essentially the same. Conversely, differences in coherence between the two hurricane categories and the tropical storm case are evident. These results suggest that once a certain hurricane intensity is reached, the turbulence may be predicted with one set of turbulence curves rather than separate curves for every hurricane category.

As separation increases, coherence decreases for the highest frequencies in the flow, presumably because the dominant eddy size becomes smaller than the separation length. Saranyasoontorn et al. (2004) also found that the coherence decreased as separation increased, but in their case, the coherence decreased to non-significant values at separations $<15 \mathrm{~m}$ opposed to $60-\mathrm{m}$ separations in our cases. This difference may be related to the $10-\mathrm{m}$ grid resolution of our numerical model, but the prevalence of roll vortices in the HBL (discussed below) may produce larger coherence in the HBL as compared with onshore and non-hurricane conditions.

Streamwise coherence in the HBL differs when calculated with horizontal and vertical separations (Fig. 12). We calculate coherence between two horizontally-separated locations at $100 \mathrm{~m}$ a.s.l. (Fig. 12a-c) and also between two vertically-separated locations (Fig. 12d-f). For the calculation using vertical separations, one location is at hub height (100 m a.s.l.) while the other location is higher than the first location (i.e., at $110-190 \mathrm{~m}$ a.s.l.).

First, at a radius of $130 \mathrm{~km}$ (tropical storm case), the flow remains highly coherent $(\geq 0.6)$ for greater horizontal separations than it does for vertical separations (Fig. 12a, d). To illustrate this behaviour, coherence as a function of separation is plotted at four frequencies 


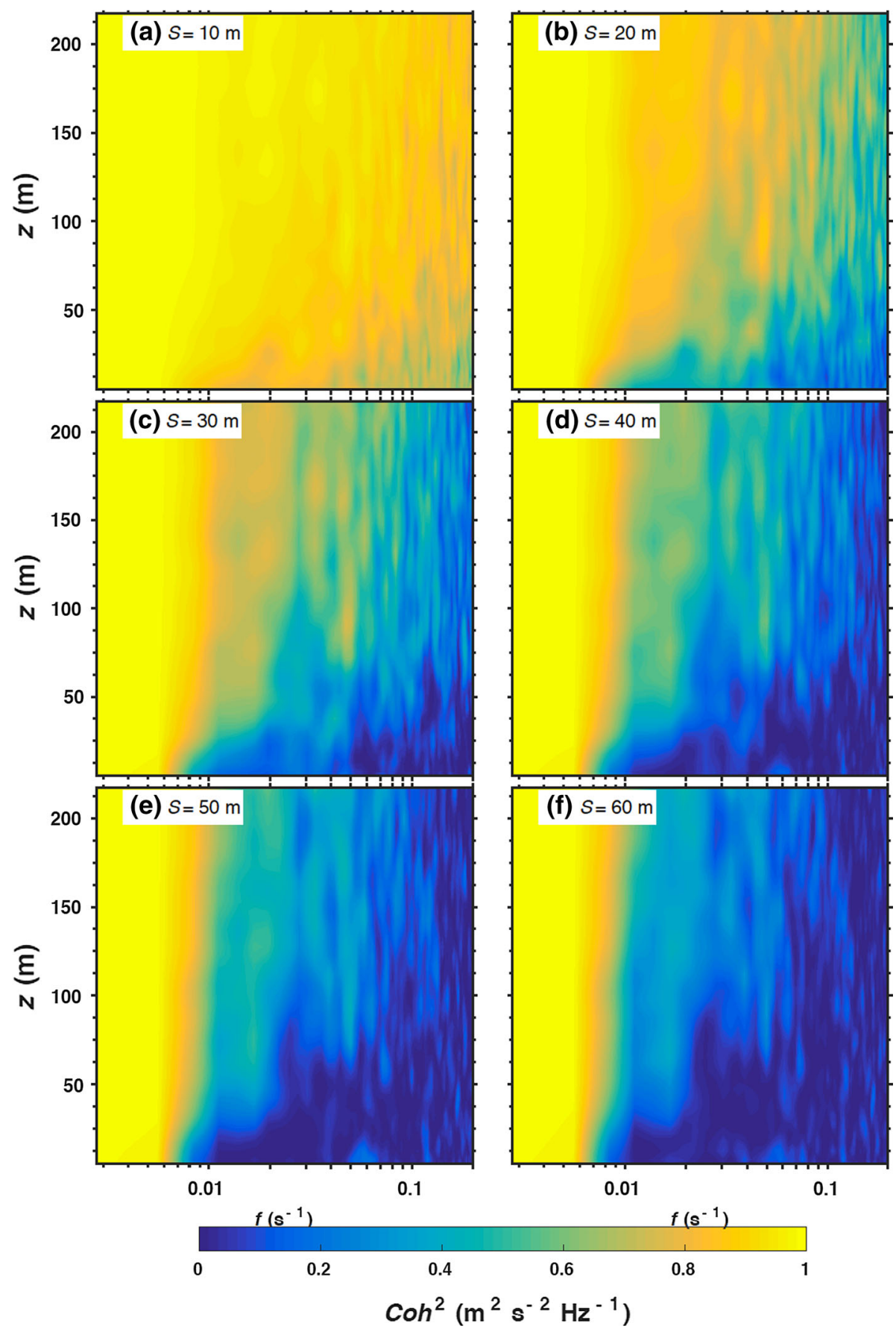

Fig. 9 Contours of spatial coherence of the streamwise velocity component at six different horizontal separations, a $10 \mathrm{~m}$, b $20 \mathrm{~m}$, c $30 \mathrm{~m}$, d $40 \mathrm{~m}$, e $50 \mathrm{~m}$, and f $60 \mathrm{~m}$ across the theoretical turbine. Data from the S10 simulation correspond to a radius of $130 \mathrm{~km}$ from the centre of the hurricane. The wind speeds at this radius represent a tropical storm case 


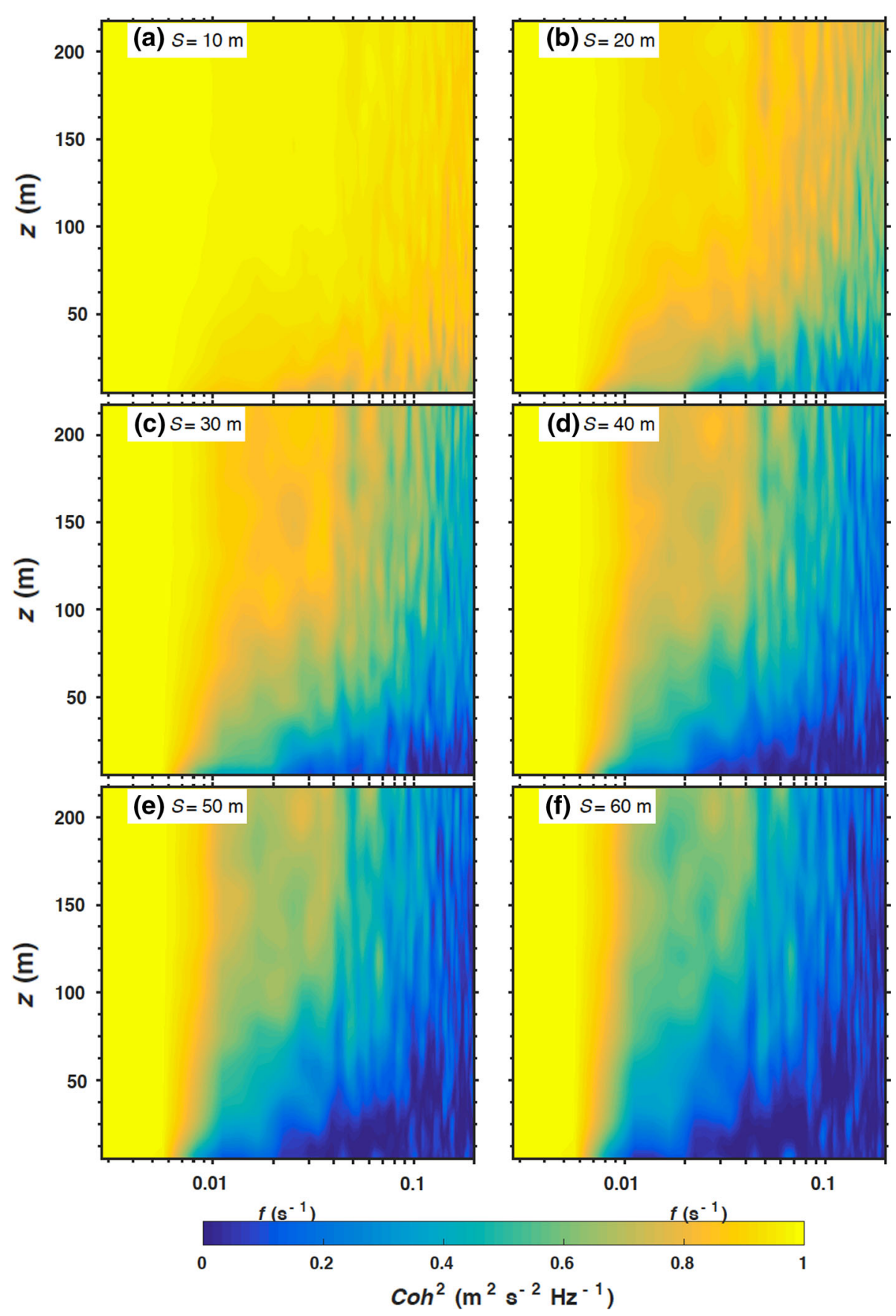

Fig. 10 Contours of spatial coherence of the streamwise velocity component at six different horizontal separations, a $10 \mathrm{~m}$, b $20 \mathrm{~m}$, c $30 \mathrm{~m}$, d $40 \mathrm{~m}$, e $50 \mathrm{~m}$, and f $60 \mathrm{~m}$ across the theoretical turbine. Data from the $\mathrm{S} 10$ simulation are from a radius of $70 \mathrm{~km}$ from the centre of the hurricane. The wind speeds at this radius represent a Category-2 case 


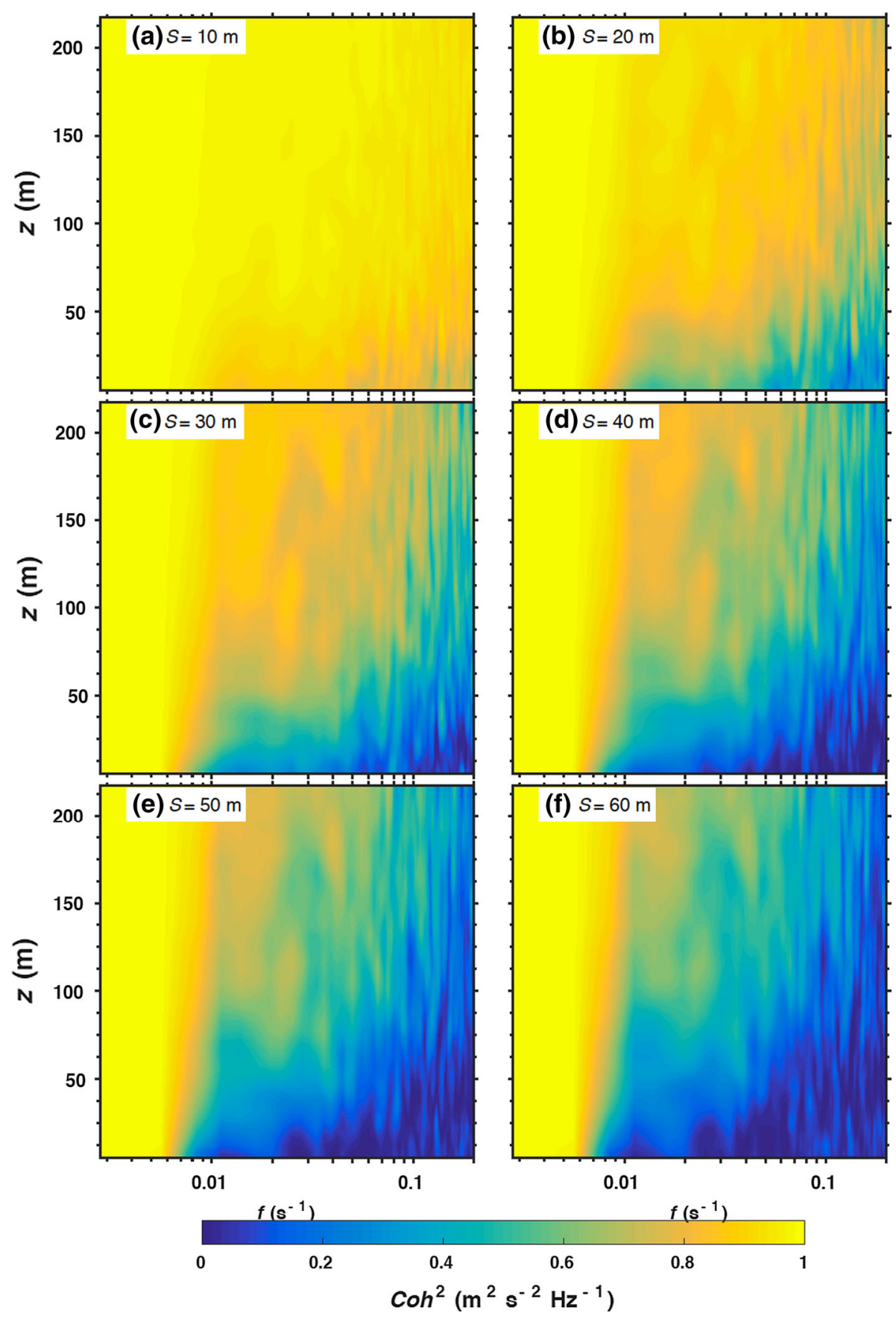

Fig. 11 Contours of spatial coherence of the streamwise velocity component at six different horizontal separations, a $10 \mathrm{~m}$, b $20 \mathrm{~m}$, c $30 \mathrm{~m}$, d $40 \mathrm{~m}$, e $50 \mathrm{~m}$, and f $60 \mathrm{~m}$ across the theoretical turbine. The data from the $\mathrm{S} 10$ simulation are from a radius of $35 \mathrm{~km}$ from the centre of the hurricane. The wind speeds at this radius represent a Category-4 case 

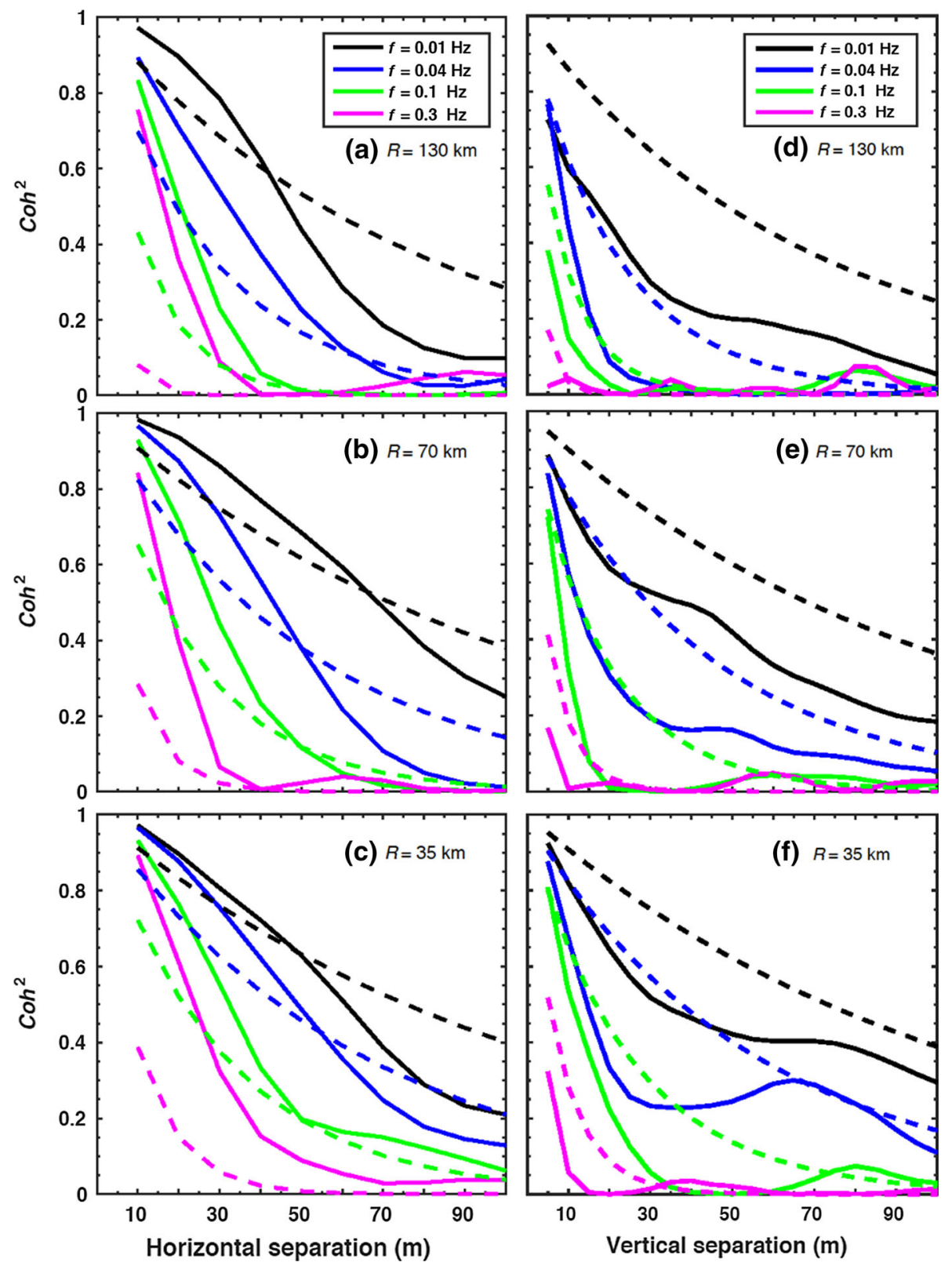

Fig. 12 Spectral coherence of the streamwise velocity component as a function of horizontal (left) and vertical (right) separation across the theoretical turbine rotor-swept area. Coherence from the S10 simulations (solid lines) and the corresponding IEC exponential coherence model (dashed lines) are displayed. The four frequencies shown are representative of some of the eddies found within the HBL

representative of the flow. Turbulence in the HBL remains highly coherent for horizontal distances as great as $45 \mathrm{~m}$ for frequencies of $0.01 \mathrm{~Hz}$ (Fig. 12a). For the same frequency, turbulence remains highly coherent for vertical distances of only15 m (Fig. 12d). 
Calculations of horizontal coherence show that large-scale turbulent structures in the HBL are very coherent for approximately $30 \mathrm{~m}$ of additional separation than that calculated for vertical coherence. This result occurs for all cases shown in Fig. 12. We suspect that the larger coherence in the horizontal direction is related to the boundary-layer roll structure of the HBL (e.g., Wurman and Winslow 1998; Nolan 2005; Morrison et al. 2005; Zhang et al. 2008; Nakanishi and Niino 2012), which is reproduced in the Simple set-up (Bryan et al. 2017).

The coherence estimates from the Simple set-up differ greatly from the empirical coherence model recommended in IEC 61400-1 (IEC 2007). The IEC exponential model (dashed lines in Fig. 12) generally predicts coherence values smaller than that of the S10 simulations for horizontal separations, except at the lowest frequency, $f=0.01 \mathrm{~Hz}$. The coherence predicted by the empirical model decreases too quickly, especially for short separations. However, as noted earlier, these differences may be related to the 10-m grid spacing of these hurricane simulations. Conversely, the coherence between two points separated by some vertical distance is slightly overestimated by the IEC coherence model.

The undulations in coherence seen in Fig. 12d-f suggest that, at a certain vertical separation, the structures in the HBL flow become similar again; the coherence does not simply decrease exponentially as vertical separation increases. Of course, these undulations occur for coherence values $<0.6$, so the flow is not highly coherent over these large separations, anyway.

Finally, we present comparisons of coherence curves best-fit for various horizontal separations in the S10 simulations to those determined by the IEC coherence model (Fig. 13). We estimate the coefficients of Eq. 4 that best represent the coherence of the flow in the HBL. Coefficients $a$ and $b$ are estimated for each storm case and for six different horizontal separations ranging from $10 \mathrm{~m}$ to $60 \mathrm{~m}$ (Table 4). The best-fit value for coefficient $a$ varies by an average absolute difference of $12 \%$ as the wind speed increases from tropical storm to Category- 2 intensity and $7 \%$ as the wind speed increases from Category-2 to Category4 intensity. A more noticeable difference in coefficient $a$ is how it varies as a function of separation. As the horizontal separation increases, coefficient $a$ increases by approximately a factor of 2 for each additional $10 \mathrm{~m}$ of separation. This sharp increase in coefficient $a$ as a function of separation is what leads to the rapid decrease in coherence as separation increases for each storm case (Fig. 13). In the HBL, the LES-based estimates of coefficient $b$ are typically smaller than that used for the IEC standard (0.12). The second term under the square root in Eq. 4 becomes insignificant when coefficient $b$ is approximately zero, which occurs frequently in the HBL as seen in Table 4.

In general, the exponential model used in the IEC standard underestimates the coherence between two points separated by some horizontal distance in the HBL (Fig. 13). We suggest that separate coherence curves be used for the separation that is most relevant for a given aspect of turbine design. For instance, if an estimation of coherence between the hub and blade tip is essential, then we recommend using the coefficients in the column ' $S=60 \mathrm{~m}$ ' to achieve the best estimate. It is possible that one coherence curve could be used to represent these three storm intensities for a certain separation, but the significance of the differences among coefficients in each storm intensity should be tested in load simulations.

\section{Discussion and Conclusions}

In the future, for wind turbines to survive Category-3, -4 and/or -5 hurricanes, designers should quantify the hurricane environment that such wind turbines are likely to experience. 
Fig. 13 Coherence calculated for four different horizontal separations, $10 \mathrm{~m}$ (black), $20 \mathrm{~m}$ (blue), $30 \mathrm{~m}$ (green), and $40 \mathrm{~m}$ (magenta). The solid lines represent the best-fits from the non-linear regression to the $\mathrm{S} 10$ simulations and the dashed lines represent the coherence predicted by the IEC exponential coherence model (Eq. 4). Three radii/hurricane intensities are displayed, a tropical storm, $\mathbf{b}$ Category-2 hurricane, and c Category-4 hurricane. The grey horizontal line shows the threshold above which the coherence is considered high $(\geq 0.6)$
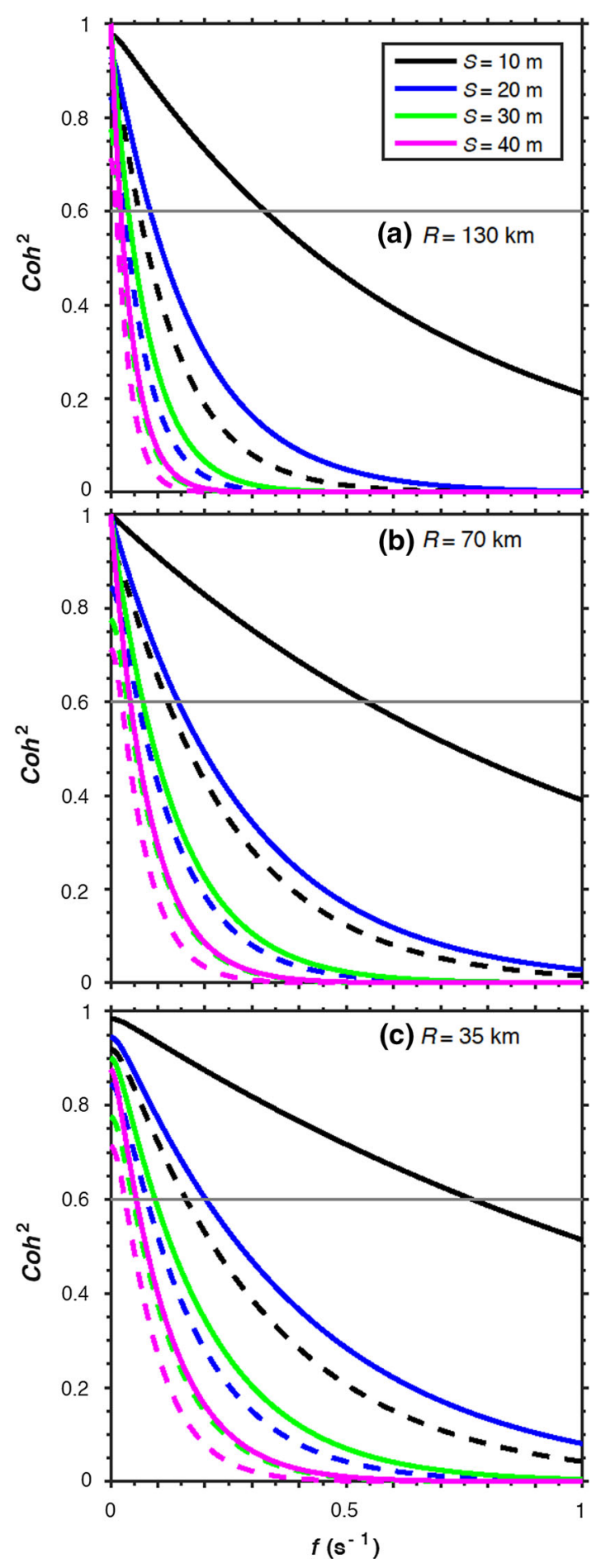
Table 4 Coefficients $a$ and $b$ for the IEC exponential coherence model (Eq. 4) (column 2) and estimates of coefficients $a$ and $b$ that best fit the coherence in the HBL for wind speeds associated with storms of tropical storm (TS), Category-2, and Category-4 intensities (columns 3-8)

\begin{tabular}{llllllcc}
\hline & IEC & $S=10 \mathrm{~m}$ & $S=20 \mathrm{~m}$ & $S=30 \mathrm{~m}$ & $S=40 \mathrm{~m}$ & $S=50 \mathrm{~m}$ & $S=60 \mathrm{~m}$ \\
\hline TS & & & & & & & \\
$a$ & 12 & 2.2269 & 4.3179 & 6.4679 & 8.5543 & 10.9075 & 13.7283 \\
$b$ & 0.12 & 0.1808 & 0.1386 & 0.0015 & 0.0001 & 0 & -0.0146 \\
Cat 2 & & & & & & \\
$a$ & 12 & 2.6972 & 5.1046 & 7.1424 & 8.7773 & 10.1455 & 11.6413 \\
$b$ & 0.12 & 0 & 0 & 0 & 0 & 0 & 0 \\
Cat 4 & & & & & & 10.8248 & 13.3475 \\
$a$ & 12 & 2.5334 & 4.7865 & 6.7304 & 8.6356 & 0.0349 & 0 \\
$b$ & 0.12 & 0.1071 & 0.1001 & 0.0883 & 0.0651 & 0.034
\end{tabular}

Coefficients for six different horizontal separations, $S$, are presented

Turbine survival during such major hurricanes introduces the possibility for lower-risk offshore wind-energy development off the USA East Coast, including the south-east USA. To assist in the understanding and design of these sturdy turbines, our study examined turbulence characteristics in the hurricane boundary layer using large-eddy simulation (LES).

In our study, an idealized Category-5 hurricane was simulated using two LES configurations (set-ups) of the CM1 model. The Complex and Simple set-ups produced similar normalized mean wind speeds, variances of the mean wind speed, and power spectral densities at altitudes of 50,100, and $200 \mathrm{~m}$ a.s.1. The results from the two configurations also compared well at multiple hurricane radii. Since the Simple set-up provides results comparable to the Complex set-up but is computationally less expensive, the Simple set-up was then used at a much higher resolution (with $\Delta x=10 \mathrm{~m}$ and $\Delta t=0.1 \mathrm{~s}$ ) to analyze power spectral density and coherence. Validation of the Simple set-up was achieved via comparisons of virtual flights through the Simple set-up domain with actual flight-level observations collected from Hurricane Isabel (2003) during the CBLAST experiment. The comparison showed that the Simple set-up can be used to estimate realistic spectra within a hurricane where, unfortunately, suitable observations of adequate spatial and temporal resolution are extremely limited.

High frequency data (available at every timestep) from simulations using the Simple set-up provided virtual mock towers over a $21 \times 21$ grid (spanning $200 \mathrm{~m} \times 200 \mathrm{~m}$ ) to quantify the power-spectral-density and coherence characteristics that a theoretical turbine based on the NREL 5-MW reference turbine (Jonkman et al. 2009) would experience in the HBL. These simulations were ran at three different radii of the overall Category-5 hurricane: 130,70 , and $35 \mathrm{~km}$, that represent three different mean wind speeds: tropical storm, Category-2, and Category-4 hurricanes, respectively.

The power-spectral-density analyses revealed that the power spectrum of the wind speed in the HBL is dependent on hurricane wind speed (or, essentially, to radius within a given hurricane, excluding the eye). The peak of the power spectral density increased in magnitude as the hurricane intensity increased (or, equivalently, as the radius decreased in a given hurricane). Additionally, as the hurricane intensity increased, eddies with frequencies as high as $0.1 \mathrm{~Hz}$ significantly contributed to the turbulent energy in the flow. The vertical extent of the peak power spectral density in the HBL also increased with increasing hurricane intensity. 
In the Category- 4 case, the greatest power in the flow extended upwards of $150 \mathrm{~m}$. Recall that the NREL 5-MW turbine-rotor layer extends from 15 to $165 \mathrm{~m}$, implying that turbines located in intense hurricanes may experience extreme loads across the entire structure.

We compared the power-spectral-density curve derived from the Simple set-up to the standard Kaimal and von Kármán spectral models, which represent a homogeneous neutral PBL and are commonly used in a class of turbulent-inflow simulators for turbine design and load estimation. The empirical and theoretical spectral models underestimated the magnitude of the power spectral density in the HBL for all hurricane intensities. Further, the peaks in the simulated power spectral densities were shifted to higher frequencies than the peaks of the standard spectral models. This shift suggests that in the HBL, the most dominant eddies in the flow have a smaller wavelength (higher frequency) than in non-hurricane conditions. Modifications of the Kaimal model were proposed to account for the greater variance and the shifted peak in turbulent energy to higher frequencies in hurricanes. Because the difference between the modified Kaimal model coefficients derived using all three storm intensities was small, particularly between the Category-2 and -4 hurricanes, we suggest one spectral curve for all cases.

Lastly, we analyzed coherence in the HBL. In general, the HBL flow remained highly coherent $(\geq 0.6$ coherence) for relatively large separations. Coherent flow between points separated horizontally by $\approx 60 \mathrm{~m}$ was apparent in the Category- 4 case. This length is nearly the entire blade length of the NREL 5-MW turbine $(\approx 63 \mathrm{~m})$. As the hurricane intensity decreased, the coherence for these separations also decreased. However, even in the tropical storm case, the flow was highly coherent for separations as large as $40 \mathrm{~m}$. The prevalence of rolls in the HBL (e.g., Wurman and Winslow 1998; Morrison et al. 2005) may explain these relatively large values of coherence. We suggest that turbine designers consider the potential additional mechanical loads induced by the prevalent and highly coherent structures with lengths corresponding to a typical turbine blade.

As with the power-spectral-density curve, we also compared the coherence curves produced from wind speeds in the hurricane cases to that generated by the IEC standard exponential model. The IEC exponential model generally underestimated the coherence for a given horizontal separation but overestimated the coherence for a given vertical separation. For these reasons, adjustments to the coefficients used in the IEC exponential model may be required.

We recognize that engineering design standards utilize simplifications that address a "worst case" loading scenario on a turbine. Our study highlights the fact that conditions in a major hurricane are likely not fully captured in the existing design standard. The results herein could be included in future design standards such as the upcoming subclass T (i.e., tropical cyclone-specific design) to be released in the fourth edition of IEC 61400-1. Additionally, our results lay the groundwork for future investigations of the impacts of hurricanes on turbine loads. Based on the power-spectral-density and coherence analyses presented here, it is likely that the loads induced inside the HBL on offshore turbines vary from those induced in non-hurricane conditions. For this reason, it is important that loads on turbines located in the HBL be assessed. The three-dimensional wind velocities produced from these large-eddy simulations can be directly included in load simulators (as in Sim et al. 2010 and Park et al. 2014) or the modified spectral and coherence curves suggested can be used to simulate the full-field of inflow in wind simulators before utilizing load simulators. Additional simulations of varying hurricane intensities may provide further insight into hurricane turbulence effects on turbines. Wind-wave interactions in coupled models may influence these results (Suzuki et al. 2014; Hara and Sullivan 2015), so LES models with both of these components could 
be used to analyze the effects of waves and the atmosphere on offshore turbines located in the HBL.

Acknowledgements This material is based upon work supported by the National Science Foundation under Grant No. DGE-1144083. We thank Branko Kosović for helping define the initial directions of this research and contributing to the spectral calculations. Additionally, we are greatly appreciative of Evan Kalina and Paul Veers for sharing their expertise of hurricanes and turbine loads, respectively. We also acknowledge high-performance computing support from Yellowstone (ark:/85065/d7wd3xhc) provided by NCAR's Computational and Information Systems Laboratory, sponsored by the National Science Foundation. We also thank the three anonymous reviewers who provided valuable feedback.

Open Access This article is distributed under the terms of the Creative Commons Attribution 4.0 International License (http://creativecommons.org/licenses/by/4.0/), which permits unrestricted use, distribution, and reproduction in any medium, provided you give appropriate credit to the original author(s) and the source, provide a link to the Creative Commons license, and indicate if changes were made.

\section{References}

Aitken ML, Kosović B, Mirocha JD, Lundquist JK (2014) Large eddy simulation of wind turbine wake dynamics in the stable boundary layer using the weather research and forecasting model. J Renew Sustain Energy 6:033137. doi:10.1063/1.4885111

Andreas EL, Mahrt L, Vickers D (2012) A new drag relation for aerodynamically rough flow over the ocean. J Atmos Sci 69:2520-2537. doi:10.1175/JAS-D-11-0312.1

Archer CL, Colle BA, Veron DL, Veron F, Sienkiewicz MJ (2016) On the predominance of unstable atmospheric conditions in the marine boundary layer offshore of the U.S. northeastern coast. J Geophys Res Atmos 121:8869-8885. doi:10.1002/2016JD024896

Bell MM, Montgomery MT, Emanuel KA (2012) Air-sea enthalpy and momentum exchange at major hurricane wind speeds observed during CBLAST. J Atmos Sci 69:3197-3222. doi:10.1175/JAS-D-11-0276.1

Bender MA, Knutson TR, Tuleya RE, Sirutis JJ, Vecchi GA, Garner ST, Held IM (2010) Modeled impact of anthropogenic warming on the frequency of intense atlantic hurricanes. Science 327:454-458. doi:10. $1126 /$ science. 1180568

Blackman R, Tukey J (1959) The measurement of power spectra. Dover, New York, 190 pp

Black PG, D'Asaro EA, Sanford TB, Drennan WM, Zhang JA, French JR, Niiler PP, Terrill EJ, Walsh EJ (2007) Air-sea exchange in hurricanes: synthesis of observations from the coupled boundary layer air-sea transfer experiment. Bull Am Meteorol Soc 88:357-374. doi:10.1175/BAMS-88-3-357

Bryan GH (2012) Effects of surface exchange coefficients and turbulence length scales on the intensity and structure of numerically simulated hurricanes. Mon Weather Rev 140:1125-1143. doi:10.1175/MWRD-11-00231.1

Bryan GH, Wyngaard JC, Fritsch JM (2003) Resolution requirements for the simulation of deep moist convection. Mon Weather Rev 131:2394-2416. doi:10.1175/1520-0493(2003)131<2394:RRFTSO>2.0.CO;2

Bryan GH, Rotunno R (2009) The maximum intensity of tropical cyclones in axisymmetric numerical model simulations. Mon Weather Rev 137:1770-1789. doi:10.1175/2008MWR2709.1

Bryan GH, Worsnop RP, Lundquist JK, Zhang JA (2017) A simple method for simulating wind profiles in the boundary layer of tropical cyclones. Boundary-Layer Meteorol 162:475-502. doi:10.1007/s10546-0160207-0

Chen X, Xu JZ (2016) Structural failure analysis of wind turbines impacted by super typhoon Usagi. Eng Fail Anal 60:391-404. doi:10.1016/j.engfailanal.2015.11.028

Cione JJ, Kalina EA, Uhlhorn EW, Farber AM, Damiano B (2016) Coyote unmanned aircraft system observations in Hurricane Edouard (2014). Earth Space Sci 3:370-380. doi:10.1002/2016EA000187

Cruz AM, Krausmann E (2008) Damage to offshore oil and gas facilities following hurricanes Katrina and Rita: an overview. J Loss Prev Process Ind 21:620-626. doi:10.1016/j.jlp.2008.04.008

Demuth JL, DeMaria M, Knaff JA (2006) Improvement of advanced microwave sounding unit tropical cyclone intensity and size estimation algorithms. J Appl Meteorol Climatol 45:1573-1581. doi:10.1175/ JAM2429.1

Department of Energy (2015) Wind vision: a new era for wind power in the United States. https://www.energy. gov/sites/prod/files/WindVision_Report_final.pdf. Accessed 27 May 2017

Dvorak MJ, Stoutenburg ED, Archer CL, Kempton W, Jacobson MZ (2012) Where is the ideal location for a US East Coast offshore grid? Geophys Res Lett 39:L06804. doi:10.1029/2011GL050659 
Hara T, Sullivan PP (2015) Wave boundary layer turbulence over surface waves in a strongly forced condition. J Phys Oceanogr 45:868-883. doi:10.1175/JPO-D-14-0116.1

Harper BA, Kepert JD, Ginger JD (2010) Guidelines For Converting Between Various Wind Averaging Periods in Tropical Cyclone Conditions. Rep, World Meteorlogical Organization Tech, p 52

Harris FJ (1978) On the use of windows for harmonic analysis with the discrete Fourier transform. Proc IEEE 66:51-83. doi:10.1109/PROC.1978.10837

International Electrotechnical Comission (2007) IEC 61400-1: Wind turbines-part 1: design requirements. 3rd edn

Ishihara T, Yamaguchi A, Takahara K (2005) An analysis of damaged wind turbines by typhoon maemi in 2003. In: Proceedings of the sixth Asia-Pacific conference on wind engineering. Seoul, South Korea

Jonkman JM, Buhl ML (2005) FAST User's Guide. National Renewable Energy Laboratory

Jonkman JM, Butterfield S, Musial W, Scott G (2009) Definition of a 5-MW reference wind turbine for offshore system development. National Renewable Energy Laboratory

Kaimal JC, Wyngaard JC, Izumi Y, Coté OR (1972) Spectral characteristics of surface-layer turbulence. Q J R Meteorol Soc 98:563-589. doi:10.1002/qj.49709841707

Kepert JD, Schwendike J, Ramsay H (2015) Why is the tropical cyclone boundary layer not "well mixed"? J Atmos Sci 73:957-973. doi:10.1175/JAS-D-15-0216.1

Larsen GC, Hansen KS (2004) Database on wind characteristics analyses of wind turbine design loads. Risø National Laboratory, Roskilde

Li L, Kareem A, Hunt J et al (2015) Turbulence spectra for boundary-layer winds in tropical cyclones: a conceptual framework and field measurements at coastlines. Boundary-Layer Meteorol 154:243-263. doi:10.1007/s10546-014-9974-7

Mirocha JD, Kosovic B, Aitken ML, Lundquist JK (2014) Implementation of a generalized actuator disk wind turbine model into the weather research and forecasting model for large-eddy simulation applications. J Renew Sustain Energy 6:013104. doi:10.1063/1.4861061

Miyake M, Stewart RW, Burling RW (1970) Spectra and cospectra of turbulence over water. Q J R Meteorol Soc 96:138-143. doi:10.1002/qj.49709640714

Morrison I, Businger S, Marks F, Dodge P, Businger JA (2005) An observational case for the prevalence of roll vortices in the hurricane boundary layer. J Atmos Sci 62:2662-2673. doi:10.1175/JAS3508.1

Nakanishi M, Niino H (2012) Large-eddy simulation of roll vortices in a hurricane boundary layer. J Atmos Sci 69:3558-3575. doi:10.1175/JAS-D-11-0237.1

National Hurricane Center Tropical Cyclone Climatology. http://www.nhc.noaa.gov/climo/. Accessed 9 Sep (2016)

Nolan DS (2005) Instabilities in hurricane-like boundary layers. Dyn Atmos Oceans 40:209-236. doi:10.1016/ j.dynatmoce. 2005.03 .002

Nolan DS, Zhang JA, Uhlhorn EW (2014) On the limits of estimating the maximum wind speeds in hurricanes. Mon Weather Rev 142:2814-2837. doi:10.1175/MWR-D-13-00337.1

Park J, Basu S, Manuel L (2014) Large-eddy simulation of stable boundary layer turbulence and estimation of associated wind turbine loads. Wind Energy 17:359-384. doi:10.1002/we.1580

Piper M, Lundquist JK (2004) Surface layer turbulence measurements during a frontal passage. J Atmos Sci 61:1768-1780. doi:10.1175/1520-0469(2004)0612.0.CO;2

Powell MD, Vickery PJ, Reinhold TA (2003) Reduced drag coefficient for high wind speeds in tropical cyclones. Nature 422:279-283. doi:10.1038/nature01481

Richter DH, Bohac R, Stern DP (2016) An assessment of the flux profile method for determining Air-Sea momentum and enthalpy fluxes from dropsonde data in tropical cyclones. J Atmos Sci 73:2665-2682. doi:10.1175/JAS-D-15-0331.1

Rose S, Jaramillo P, Small MJ, Grossmann I, Apt J (2012) Quantifying the hurricane risk to offshore wind turbines. Proc Natl Acad Sci 109:3247-3252. doi:10.1073/pnas.1111769109

Saranyasoontorn K, Manuel L, Veers PS (2004) A comparison of standard coherence models for inflow turbulence with estimates from field measurements. J Sol Energy Eng 126:1069-1082. doi:10.1115/1. 1797978

Siebesma AP, Bretherton CS, Brown A et al (2003) A large eddy simulation intercomparison study of shallow cumulus convection. J Atmos Sci 60:1201-1219. doi:10.1175/1520-0469(2003)602.0.CO;2

Sim C, Manuel L, Basu S (2010) A comparison of wind turbine load statistics for inflow turbulence fields based on conventional spectral models and large eddy simulation. In: Proceedings of 48th AIAA Aerospace Science Meeting Orlando, FL

Sommeria G (1976) Three-dimensional simulation of turbulent processes in an undisturbed trade wind boundary layer. J Atmos Sci 33:216-241. doi:10.1175/1520-0469(1976)0332.0.CO;2

Stern DP, Bryan GH, Aberson SD (2016) Extreme low-level updrafts and wind speeds measured by dropsondes in tropical cyclones. Mon Weather Rev 144:2177-2204. doi:10.1175/MWR-D-15-0313.1 
Stevens B, Moeng C-H, Sullivan PP (1999) Large-eddy simulations of radiatively driven convection: sensitivities to the representation of small scales. J Atmos Sci 56:3963-3984. doi:10.1175/1520-0469(1999)0562. $0 . \mathrm{CO} ; 2$

Suzuki N, Hara T, Sullivan PP (2014) Impact of dominant breaking waves on Air-Sea momentum exchange and boundary layer turbulence at high winds. J Phys Oceanogr 44:1195-1212. doi:10.1175/JPO-D-130146.1

Thresher RW, Holley WE, Smith CE, Jafarey N, Lin SR (1981) Modeling the response of wind turbines to atmospheric turbulence. Oregon State University, Corvallis (USA). Department of Mechanical Engineering. DOE/ET/23144-81/2

Vickery PJ, Skerlj PF (2005) Hurricane gust factors revisited. J Struct Eng 131:825-832. doi:10.1061/ (ASCE)0733-9445(2005)131:5(825)

von Kármán TV, Lin CC (1951) On the statistical theory of isotropic turbulence. In: Kármán RVM and TV (ed) Advances in applied mechanics. Elsevier, Amsterdam, pp 1-19

Wang H, Barthelmie RJ, Pryor SC, Kim HG (2014) A new turbulence model for offshore wind turbine standards. Wind Energy 17:1587-1604. doi:10.1002/we.1654

Wicker LJ, Skamarock WC (2002) Time-splitting methods for elastic models using forward time schemes. Mon Weather Rev 130:2088-2097. doi:10.1175/1520-0493(2002)130<2088:TSMFEM>2.0.CO;2

Wurman J, Winslow J (1998) Intense sub-kilometer-scale boundary layer rolls observed in Hurricane Fran. Science 280:555-557. doi:10.1126/science.280.5363.555

Yu B, Chowdhury AG, Masters FJ (2008) Hurricane wind power spectra, cospectra, and integral length scales. Boundary-Layer Meteorol 129:411-430. doi:10.1007/s10546-008-9316-8

Zhang JA (2010a) Spectral characteristics of turbulence in the hurricane boundary layer over the ocean between the outer rain bands. Q J R Meteorol Soc 136:918-926. doi:10.1002/qj.610

Zhang JA (2010b) Estimation of dissipative heating using low-level in situ aircraft observations in the hurricane boundary layer. J Atmos Sci 67:1853-1862. doi:10.1175/2010JAS3397.1

Zhang JA, Drennan WM (2012) An observational study of vertical eddy diffusivity in the hurricane boundary layer. J Atmos Sci 69:3223-3236. doi:10.1175/JAS-D-11-0348.1

Zhang JA, Katsaros KB, Black PG, Lehner S, French JR, Drennan WM (2008) Effects of roll vortices on turbulent fluxes in the hurricane boundary layer. Boundary-Layer Meteorol 128:173-189. doi:10.1007/ s10546-008-9281-2

Zhang JA, Drennan WM, Black PG, French JR (2009) Turbulence structure of the hurricane boundary layer between the outer rainbands. J Atmos Sci 66:2455-2467. doi:10.1175/2009JAS2954.1

Zhang JA, Marks FD, Montgomery MT, Lorsolo S (2010) An estimation of turbulent characteristics in the low-level region of intense hurricanes Allen (1980) and Hugo (1989). Mon Weather Rev 139:1447-1462. doi:10.1175/2010MWR3435.1

Zhang JA, Rogers RF, Nolan DS, Marks FD (2011) On the characteristic height scales of the hurricane boundary layer. Mon Weather Rev 139:2523-2535. doi:10.1175/MWR-D-10-05017.1 